\section{放射線滅菌法に打ける 包装材の検討}

\section{細 㴊 和 成}

1956年米国エチコン社が腸線縫合系の減菌に放射線 滅菌法を世界で初めて実用化して以来, ここ十数年の 間に医療用具の放射線隇菌法が急速に発展してきた。 このような放射線隇菌法の発展には, 高分子化学の発 展が多大に寄与したことはいうまでもない。

放射線隇菌法は，熱を利用しない，包装後隇菌でき るという利点を生かし，現在日本に执いては，注射 筒, 注射針, 替刃メス, 栄養カテーテル, 人工腎䁍透 析器など十数種目のディスポーザブル医療用具の滅菌 に利用され，医療分野の合理化，省力化，院内感染防 止に役立っている。

ここでは, 包装材料のみではなく放射線減菌法に招 ける包装全般の問題について, Powell ${ }^{1,2)}$ の論旨に従 って各文献を紹介したい。

包装の目的 ${ }^{3), 41}$ は,

○包装が開封されるまで包装内の製品が無菌状態を 保持できること。

○製品を污染することなく取り出すことができるこ である。

と（取り出しやすい）。

この目的のために，第一に包装材の材質が問題とな る。放射線に安定な材質を選ぶことが必要となるが， ガラスや金属ではコストおよび取り扱い上で問題が多 すぎる。そこで，ポリマーが考えられる。しかしな がら, 低線量 $400 \mathrm{~Gy}\left(4 \times 10^{4} \mathrm{rad}\right)$ で変化する polytetrafluoroethylene から高線量 $50 \mathrm{MGy}\left(5 \times 10^{9} \mathrm{rad}\right)$ で 变化する polystyrene や polyamides のように多種類の ポリマーが存在するら。このため, 一般に用いられて いる滅菌線量 $25 \mathrm{kGy}(2.5 \mathrm{Mrad})$ に対して比較的安定 な材質が選ばれている。たとえば, polyethylene, polystyrene, polyesters, polyamides, cellulosics, polycarbonate, そしてこれら 2 種以上のラミネートしたものな ぞが使われている(い) 。

第二の問題として，使用までの製品の無菌状態の確 保である。つまり，有効期間の問題である。一般に放 射線隇菌された製品の有効期間は他の隇菌法と比べて 比較的長く, 仏国薬局方 ${ }^{9}$ では 2 力年としている。し かし，放射線照射した包装（たとえば， polypropylene） が経時的に劣化する場合が考えられるため, 放射線隇 菌法の製造承認を得る場合, 製品（包装を含む）の 6 カ月以上の材質試験が要求されている ${ }^{10)}$ 。

材質面で安定でも, 保存状態が悪ければ無菌は確保 できない。また，製品が鋭利なものであれば，持ち 運び等によりピンホールが生じる可能性は高い。 Christensen ${ }^{2)}$ はいろいろな理由でディスポーザブル医 療用具の包装に約10\%のピンホールが認められたと報 告している。
第三に, 開封時の污染を少なくするために包装方法 扰よび開封方法にいろいろな工夫がなされている。透 過力の強い $\gamma$ 線で減菌するからといって厳重に包装し ても，使用時簡単に開封できなくては製品の污染する 可能性は高い。厳重に, そして簡単に開封できる包装 が望まれるところである。その意味で二重包装, ピー ル包装は代表的な包装形態である。

包装材の材質および形態面を取り上げてきたが，最 近 Bioburden の考え方が放射線隇菌法に導入されてき $た^{11), 12)}$ 。米国薬局方 ${ }^{13)}$ 亿打いて子, 隇菌線量の低減 化のため, Bioburden の測定の重要性を述べている。 Bioburden とは被隇菌物の污染菌 (数, 種類, 減菌抵 抗性）をいう。このため, 包装材の污染菌数を知るこ とは大切なことである。佐藤 ${ }^{14}$ は包装の内側よりも外 側が，また包装の表面に印刷されていないものよりも 印刷されているものが菌数が多いと報告している。

このように包装にはいろいろな問題があげられる。 そして, 包装は滅菌済及製品にとって隇菌法とともに 重要な意味を持つことを心に銘記しなければならな w。

\section{文献}

1) G.B. Phillips (Ed): Industrial Sterilization, Duke Univ. Press (1972)

2) D.B. Powell: Manual on Radiation Sterilization of Medical and Biological Materials, IAEA (1973)

3) M.E. Huth: Sterilization and Packaging, First World Conference of Operating Room Nurses (1978)

4) A. Osol (Ed.): Remington's Pharmaceutical Sciences (1975)

5) W.E. Skiens: Radiat. Phys. Chem., 15, 47 (1980)

6) N.G.S. Gopal: ibid., 12, 35 (1978)

7) H. Landfield: ibid., 15, 39 (1980)

8) B.P. Evans: ibid., 15, 75 (1980)

9) The French Pharmacopeia 9th Ed. (1976)

10）厚生省薬務局審査課監修：医療用具製造申請の 手引，薬事日報社（1979）

11) E.R.L. Gaughran (Ed.): Sterilization of Medical Products by Ionizing Radiation, Multiscience Publication Ltd. (1978)

12) J.L. Whitby: Radiat. Phys. Chem., 14, 285 (1979)

13) The United States Pharmacopeia 20th Ed. (1980)

14）佐藤健二 : 医器学, 43, 400 (1973)

（東京都立アイソトープ総合研究所） 
理工文献紹介

${ }^{3} \mathrm{H}$ 増殖用ブランケットによる

\section{${ }^{3} \mathrm{H}$ の製造}

那 須 昭 -

地上で実現できる核融合反応の中では，次式に示す 重水素(D)とトリチウム $(\mathrm{T})$ を融合する D-T 反応が最 も容易である。そこで, 最初の核融合炬は, 炬形の種 類によらず， D-T 怇をめざしている。

$$
\mathrm{D}+\mathrm{T} \rightarrow{ }^{4} \mathrm{He}(3.5 \mathrm{MeV})+n(14.1 \mathrm{MeV})
$$

D-T 炉では， D-T 反応で生成する14. $1 \mathrm{MeV}$ の中性 子を利用して，ブランケット内でTを自己生産する。 このように，D-T 炬では，炬心のまわりに Tを生産 するブランケットを持つ。ブランケットには，Tを生 産する親物質の液体 $\mathrm{Li}$ なた $\mathrm{Li}$ を含む合金やセラミ ックスが収納されている。

天然の $\mathrm{Li}$ には, ${ }^{6} \mathrm{Li}$ が $7.42 \%,{ }^{7} \mathrm{Li}$ が $92.58 \%$ 含ま れて拈りそそれぞれ次の上らに中性子と反応する。

$$
\begin{aligned}
& { }^{7} \mathrm{Li}+n \rightarrow{ }^{4} \mathrm{He}+\mathrm{T}+n^{\prime}-2.47 \mathrm{MeV} \\
& { }^{6} \mathrm{Li}+n \rightarrow{ }^{4} \mathrm{He}+\mathrm{T}+4.78 \mathrm{MeV}
\end{aligned}
$$

すなわち, プラズマの $\mathrm{D}-\mathrm{T}$ 反応で $\mathrm{T}$ 個消費し， 中性子を 1 個生成する。この中性子は，上式の上うに Tを 2 個生成し，Tが増殖される。

ブランヶット方式には，液体方式と固体方式が提案 されている(表 1)。T親物質は, 液体 $\mathrm{Li}, \mathrm{Li}_{7} \mathrm{~Pb}_{2}, \mathrm{Li}_{2} \mathrm{O}$, $\mathrm{Li}_{2} \mathrm{SiO}_{3}$ ，および $\mathrm{LiAlO}_{2}$ にしばられており,フライベ やLiAl は影がうすくなっている。これら Li を含む材 料について, 融点, 密度和よび $\mathrm{Li}$ 原子密度を表 2 に示 す。液体 Liを除けば他はすべて固体として使用する。 $\mathrm{Li}_{7} \mathrm{~Pb}_{2}$ は多くの点で $\mathrm{LiAl}$ に似ている。中性子増倍剂 の $\mathrm{Pb}$ を含むので, T増殖能力は高い。しかし, 融点 が低いので，炉の運転温度は低くなる。 $\mathrm{Li}_{2} \mathrm{O}$ は $\mathrm{Li}$ 化 合物の中で $\mathrm{Li}$ 原子密度が最も高く, 融点も比較的高 い興味ある T親物質である。 $\mathrm{Li}_{2} \mathrm{SiO}_{3}$ と $\mathrm{LiAlO}_{2}$ は高 温で比較的安定な化合物で, 複合化合物としてはLi原 子密度は高い。しかし，Tを增殖するには中性子增倍 材を必要とする。

$\mathrm{T}$ 增殖に関連した表 2 に示す固体 $\mathrm{T}$ 親物質からの $\mathrm{T}$ 放出の研究は, 日本 $(\text { 原研 })^{1) \sim 7}$, 米国 $\left(\mathrm{BNL}^{8)}, \mathrm{PNC}\right.$

\begin{tabular}{|c|c|c|c|}
\hline \multicolumn{2}{|c|}{$\mathrm{T}$ 親物 質 } & \multirow{2}{*}{ 冷却材料 } & \multirow{2}{*}{ 設 計 例 } \\
\hline & 組 成 & & \\
\hline $\begin{array}{l}\text { 液 } \\
\text { 体 }\end{array}$ & $\mathrm{Li}$ & $\begin{array}{l}\mathrm{Li} \\
\text { フライベ } \\
\mathrm{He}\end{array}$ & $\begin{array}{l}\text { UWMAK-I } \\
\text { HFCTR } \\
\text { UWMAK-III, KFA } \\
\text { ORNL-DEMO }\end{array}$ \\
\hline $\begin{array}{l}\text { 固 } \\
\text { 体 }\end{array}$ & $\begin{array}{l}\mathrm{Li}_{2} \mathrm{O} \\
\mathrm{LiAlO}_{2}\end{array}$ & $\begin{array}{c}\mathrm{He} \\
\mathrm{Li}_{2} \mathrm{O} \\
\mathrm{He}\end{array}$ & $\begin{array}{l}\text { JXFR } \\
\text { SOLASE } \\
\text { UWMAK-II }\end{array}$ \\
\hline
\end{tabular}
$\left.{ }^{9}\right)$, 西独 $(\mathrm{KFA})^{10), 11)}$ ，ソ連 ${ }^{12}$ の各グループによりそ

表 1 核融合炉ブランケット方式の分類と設計例
れぞれ進められている。しかし，各グループで用いた 試料はほとんどが粉末で, 試料のキャラクタリゼーシ ョンに問題を残している。実験法はすべて照射後焼釷 法である。すなわち，T放出の温度範囲が得られる等 時焼鈍法, およびT放出の速度式や活性化エネルギー が得られる等温焼鈍法や等速昇温法により T放出が調 べられている。粉末以外飞, $\mathrm{Li}_{2} \mathrm{O}$ 焼結体ペレットおよ び単結晶を使用し, T放出の気孔率依存性も調べられ ている3 ${ }^{3)}$ )。乙かし, 結晶粒寸法依存性, 照射量依存 性，不純物や格子欠陷による捕獲効果など，解明すべ き点が多く残されている。な技，照射後焼鈍法よりる より現実に近い照射下に护る $\mathrm{Li}_{2} \mathrm{O}$ 焼結体ペレット からのT放出実験が原研で進められている。

$\mathrm{T}$ 親物質が，粉末もしくは粉末に近い形で使用され る場合は，反跳によるT放出が無視できなくなる。反 跳による $\mathrm{Li}_{2} \mathrm{O}$ からのT放出の研究も進められており, $\mathrm{Li}_{2} \mathrm{O}$ 中の $2.7 \mathrm{MeV}$ の $\mathrm{T}$ 飛程などが求められている 6), ,7)

\section{文献}

1) H. Kudo, et al.: Radiochem. Radioanal. Letters, 23, 57 (1975)

2) K. Tanaka, et al.: Proc. Int. Conf. on Radiation Effects and Tritium Technology for Fusion Reactors, Gatlinberg, Tenn., p. 253 (1975)

3) S. Nasu, et al.: J. Nucl. Mater., 68, 261(1977)

4) H. Kudo, et al.: J. Inorg. Nucl. Chem., 40, 363 (1978)

5) T. Tanifuji, et al.: J. Nucl. Mater., in press

6) M. Akabori, et al.: ibid., 83, 330 (1979)

7) K. Uchida, et al.: ibid., 89, 92 (1980)

8) R.H. Wiswall, et al. : BNL-19766 (1975), BNL-20563 part 2 (1975), BNL-50748 (1977)

9) A.B. Johnson, Jr.: BNWL-2116 (1976)

10) D. Guggi, et al.: Proc. Int. Conf. on Radiation Effects and Tritium Technology for Fusion Reactors, Gatlinberg, Tenn., p. 416 (1975)

11) D. Guggi, et al.: Proc. 9th Symp. on Fusion Technology, p. 337 (1976)

12) V.G. Vasiliev, et al.: US/USRR Workshop on Engineering and Economic Problems of ETF (1979)

（日本原子力研究所 東海研究所）

表 $2 \mathrm{Li}, \mathrm{Li}$ 合金および $\mathrm{Li}$ セラミックスの融点, 密度, $\mathrm{Li}$ 原子密度

\begin{tabular}{c|r|c|c}
\hline $\mathrm{T}$ 親 物 質 & 融点 $(\mathrm{K})$ & 密度 $\left(\mathrm{g} \cdot \mathrm{cm}^{-3}\right)$ & $\begin{array}{c}\mathrm{Li} \text { 原子密度 } \\
\left(\mathrm{g} \cdot \mathrm{cm}^{-3}\right)\end{array}$ \\
\hline $\mathrm{Li}$ & 453 & 0.51 & 0.51 \\
$\mathrm{Li}_{7} \mathrm{~Pb}_{2}$ & 999 & 4.59 & 0.49 \\
$\mathrm{Li}_{2} \mathrm{O}$ & 1700 & 2.01 & 0.93 \\
$\mathrm{Li}_{2} \mathrm{SiO}_{3}$ & 1470 & 2.52 & 0.36 \\
$\mathrm{LiAlO}_{2}$ & 1880 & 2.60 & 0.27 \\
\hline
\end{tabular}




\section{（0） 総説，データ集等}

20863 Abstracts of Papers Presented at the International Conference on Liquid Scintillation Counting

Anon.: Intern. J. Appl. Rad. \& Isotopes, 31, (1) 1 (1980)

20864 Nuclear Analytical Methods in Geochemistry and Geophysics

H. Huebner, et al.: Isotopenpraxis, 16, (2) $37 \sim 51$ (1980)

\section{（1）基礎拈よび一般}

\section{(1・1) 物 理}

20865 Decay Data of ${ }^{67} \mathrm{Ga}$ and ${ }^{201} \mathrm{Tl}$

K. Debertin, et al.: Intern. J. Appl. Rad.

\& Isotopes, 30, (9) 551 (1979)

20866 Yield of ${ }^{73} \mathrm{Se}$ for Various Reactions and

Its Chemical Processing

T. Nozaki, et al.: ibid., 30, (10) 595 (1979)

20867 Production of Astatine and Radon Isotopes

by Photospallation of ${ }^{232} \mathrm{Th}$ and ${ }^{238} \mathrm{U}$

J. Visser, et al.: ibid., 30, (12) 745 (1979)

$20868{ }^{76} \mathrm{Br}$ and ${ }^{77} \mathrm{Br}$ from Decay of Cyclotron Produced ${ }^{76} \mathrm{Kr}$ and ${ }^{77} \mathrm{Kr}$

D. de Jong, et al.: ibid., 30, (12) 786 (1979)

$20869 \gamma$-Ray Emission Probabilities and Half-life of ${ }^{139} \mathrm{Ba}$

R.J. Gehrke: ibid., 31, (1) 37 (1980)

20870 Neutron Yield of $(\alpha, n)$ Reaction on Oxygen

V.I. Bulanenko: Soviet Atomic Energy, 47,
(1) 531 (1979)

20871 Calculation of Photoneutron Yields from Thick Targets in Giant-resonance Region V.I. Isaev, et al.: ibid., 47, (1) 538 (1979)

20872 Effects of Various Factors on the Absorbed-dose Distribution in Thin Layers V.V. Krayushkin: ibid., 47, (1) 552 (1979)

20873 The Thermal-neutron Fission Cross Section and the Fission-resonance Integral for ${ }^{243} \mathrm{Cm}$

K.D. Zhuravlev, et al.: ibid., 47, (1) 565 (1979) 20874 Backscattering Coefficients of Electrons G.B. Radzievskü: ibid., 47, (2) 646 (1979)

$$
\text { (1-2) 化 学 }
$$

20875 Size and Charge Distributions of Radiocolloid Particles

T.K. Lim, et al.: Intern. J. Appl. Rad. \& Isotopes, 30, (9) 531 (1979)

20876 Mise au d'une technique d'autoradiographie à haut pouvoir de résolution sur lames minces. Application au cas du radiotraceur ${ }^{14} \mathrm{C}$ dans des aciers inoxydables G.V. Prabhu Gaunkar, et al.: ibid., 30, (10) 601 (1979)

20877 Polymer Formation and Hydrolysation of ${ }^{99} \mathrm{Tc}$ (IV)

E. Sundrehagen: ibid., 30, (12) 739 (1979)

20878 Solubility Coefficients of ${ }^{133} \mathrm{Xe}$ in Water, Saline, Dog Blood and Organs M.T. Ercan: ibid., 30, (12) 753 (1979)

20879 Investigations of the Influence of $\mathrm{Fe}^{3+}$. Ions on the Speed of the Photolysis of the System $\left[1-{ }^{14} \mathrm{C}\right]$ Tributyltinoxide/Cellulose D. Kloetzer: Isotopenpraxis, 16, (2) 56 58

\begin{tabular}{|c|c|c|c|c|}
\hline \multicolumn{5}{|c|}{ 分 類 項 目 表 (1977年 1月 分類項目一部改訂) } \\
\hline （0） 総説，データ集等 & $(3 \cdot 4)$ & 高分子と重合 & $(6 \cdot 1)$ & 測定法 \\
\hline （1）基礎扰よび一般 & $(3 \cdot 5)$ & その他 & $(6 \cdot 2)$ & 検出部 \\
\hline$(1 \cdot 1)$ 物理 & (4) $\vdash$ & 一サ利用 & $(6 \cdot 3)$ & 測定機器 \\
\hline$(1 \cdot 2)$ 化学 & $(4 \cdot 1)$ & 物理的トレーサ & $(6 \cdot 4)$ & その他 \\
\hline (1.3) その他 & $(4 \cdot 2)$ & 化学的トレーサ & (7) 同位 & 体の製造・分離 \\
\hline （2）線源とその利用 & $(4 \cdot 3)$ & アクチバブルトレーサ & $(7 \cdot 1)$ & 製造・分離・精製 \\
\hline$(2 \cdot 1)$ 線源 - 加速器 - 照射装置 & $(4 \cdot 4)$ & 年代学的利用 & $(7 \cdot 2)$ & 標識化合物 \\
\hline (2・2) ラジオグラフィ & $(4 \cdot 5)$ & その他 & $(7 \cdot 3)$ & その他 \\
\hline （2・3） 応用計測および装備機器 & （5）分 & 析 & （8）放身 & 寸線の管理とその防護 \\
\hline (2.4) その他 & $(5 \cdot 1)$ & 放射化分析 & $(8 \cdot 1)$ & 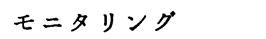 \\
\hline （3）放射線照射効果 & $(5 \cdot 2)$ & 放射化学的分析 & $(8 \cdot 2)$ & 施設お゙よび取扱い \\
\hline (3.1) 物理的効果 & $(5 \cdot 3)$ & 質量分析 & $(8 \cdot 3)$ & 遮 蔽 \\
\hline （3・2） 単体および無機化合物 & $(5 \cdot 4)$ & その他 & $(8 \cdot 4)$ & 廃棄物処理 \\
\hline （3·3） 有機化合物 & （6） 測 & および測定機器 & $(8 \cdot 5)$ & その他 \\
\hline
\end{tabular}




\section{(1980)}

20880 Dependencies of $\mathrm{pH}$ and Current Density on the Isotope Effect Occurred by the Electromigration of Uranyl Ions in a Cation Exchange Membrane

M. Okamoto, et al.: ibid., 16, (2) 58 61 (1980)

20881 Isotope Effects in Atom Transfer Reactions in the Gaseous Phase. I.

H. Johansen, et al.: ibid., 16, (2) 61 65 (1980)

20882 A Xenon Component of Anomalous Isotopic Composition in Terrestrial Materials Irradiated with Neutrons

H. Gerstenberger: ibid., 16, (3) 88 91(1980)

$$
\text { (1.3) そ の 他 }
$$

20883 Absorbed Dose to Ovaries or Uterus during a ${ }^{131} \mathrm{I}$-therapeutic of Cancer or Hyperthyroidism: Comparison between in vivo Measurements by TLD and Calculations

J. Briere, et al.: Intern. J. Appl. Rad. \& Isotopes, 30, (10) 643 (1979)

20884 A Thick-target Radiation Transport Computer Code for Low-mass Heavy Ion Beams T.W. Armstrong, et al.: Nucl. Instr. \& Methods, 169, (1) 161 (1980)

\section{（2）線源とその利用}

\section{（2・1）線源・加速器・照射装置}

20885 The Preparation of Thin $\alpha$-particle Sources from Solutions at Low Concentrations

C.J. Bland: Intern. J. Appl. Rad. \&

Isotopes, 30, (9) (1979)

20886 On the Advancement of the Manganese-

Bath Method for the Determination of the

Source Strength Unit of Radioactive Neutron Sources at ASMW

K. Groche, et al.: Isotopenpraxis, 16, (2) 51 $\sim 56$ (1980)

20887 An Accelerating Section for Reducing the Radiation Level in the Absorber Section of a Linac

V.S. Balagura, et al.: Soviet Atomic Energy, 47, (1) 543 (1979)

\section{（2·3）応用計測および装備機器}

20888 Non-destructive Analysis of Silver Alloys by Means of Low Energy $\gamma$-rays and Neu- tron Transmission Measurements

R. Cesareo, et al.: Intern. J. Appl. Rad.

\& Isotopes, 30, (10) 589 (1979)

20889 Selection of Polychlorinated Plastics in Plastic Waste by X-ray Fluorescence Method H. Kumasaki, et al.: ibid., 30, (10) 637 (1979)

$$
\text { (2.4) そ の 他 }
$$

20890 Effect of Atmospheric Carbon Dioxide on the Terephthalate Dosimeter

R.W. Matthews, et al.: Intern. J. Appl. Rad. \& Isotopes, 30, (11) 716 (1979)

\section{（3）放射線照射効果}

\section{(3・1) 物理的効果}

20891 Nanosecond Time-resolved EPR in Pulse Radiolysis via the Spin Echo Method

A.D. Trifunac, et al.: J. Chem. Phys., 71, (11) 4380 (1979)

20892 Effects of Bombardment by $\mathrm{He}^{+}, \mathrm{Ni}^{+}$, and $\mathrm{Cr}^{+}$on Microhardness and Corrosion Cracking of Stainless Steels

B.G. Vladimirov, et al.: Soviet Atomic Energy, 47, (1) 558 (1979)

20893 Effects of Ion-bombardment Dose and Previous Surface Treatment on the Erosion of Molybdenum

B.A. Kalin, et al.: ibid., 47, (1) 562 (1979)

\section{（3・2） 単体および無機化合物}

20894 High Power Electron Spin Echo Modulation Studies of Silver Atom Solvation and Desolvation in Ice Matrices: Geometrical Models for Silver Cation and Silver Atom Aqueous Solvation Shells

T. Ichikawa, et al.: J. Chem. Phys., 71, (9) 3792 (1979)

20895 Radiation Damage Studies by X-ray Photoelectron Spectroscopy. III. Electron Irradiated Halates and Perhalates

T. Sasaki, et al.: ibid., 71, (11) 4601 (1979)

20896 Mechanism of Thermal Electron Attachment in $\mathrm{O}_{2}-\mathrm{C}_{2} \mathrm{H}_{4}, \mathrm{O}_{2}-\mathrm{CO}_{2}$, and $\mathrm{O}_{2}$-neopentane Mixtures

Y. Kokaku, et al.: ibid., 71, (12) 4883 (1979)

20897 Examination of Irradiated Metal Diborides by X-ray Diffraction

Kh. É. Maile, et al.: Soviet Atomic Energy, 47, (1) 548 (1979) 


\section{（3·3） 有機化合物}

20898 An ESR Study of Chlorine Containing Radicals in X-irradiated N-chlorosuccinimide at $77^{\circ} \mathrm{K}$

D. Pace, et al.: J. Chem. Phys., 71, (10) 3971 (1979)

20899 The Radiolysis of Dodecane-tributylphosphate Solutions. II. Liquid Products

J. Razvi, et al.: Nucl. Instr. \& Methods, 169, (1) 223 (1980)

\section{（3・4）高分子と重合}

20900 Improvement in Physical Properties of Poly(vinyl Chloride) by Radiation-induced Graft Copolymerization with Mixed Monomers

H. Omichi, et al.: J. Appl. Polymer Sci., 22, (12) 3387 (1978)

20901 Thermal Analysis of Polyethylene Prepared by $\gamma$-ray-induced Polymerization in Various Solvents

H. Arai, et al.: ibid., 22, (12) 3485 (1978)

$20902 \gamma$-Radiation-induced Telomerization of Vinyl Acetate, Styrene, and Methyl Methacrylate

O. Altmann, et al.: ibid., 23, (1) 215 (1979)

20903 Preparation and Properties of Radiationgrafted Membranes for Eliminating Sodium Alkylbenzenesulfonate from Water

H. Yamakita, et al.: ibid., 23, (1) 303 (1979)

20904 Radiation-induced Graft Copolymerization of Methyl Methacrylate on Natural and Modified Wool. II. Sorption Behavior

D.S. Varma, et al.: ibid., 23, (2) 393 (1979)

20905 Synergistic Effect in $\gamma$-irradiated Poly (vinyl Chloride) Hard Foils Stabilized by Plasticizer-Stabilizer Systems

W. Szymański, et al.: ibid., 23, (3) 791 (1979)

20906 Heat Curing of Radiation-induced Crosslinked Syndiotactic 1, 2-polybutadiene

H. Okamoto, et al.: ibid., 23, (6) 1893 (1979)

20907 Pervaporation Membranes Prepared by Radiochemical Grafting of N-vinylpyrrolidone onto Films

G. Morel, et al.: ibid., 23, (8) 2397 (1979)

20908 Flame Resistant Cotton Fabrics Prepared by Radiation-initiated Polymerization with Vinyl Phosphonate Oligomer and $\mathrm{N}$ methylolacrylamide

J.A. Harris, et al.: ibid., 23, (9) 2555 (1979)
20909 The Radiation-induced Emulsion Copolymerization of Vinyl Chloride with Vinyl Acetate in an Engineering Flow System J.T. Tsai, et al.: ibid., 23, (9) 2701 (1979)

20910 Transparent Fluorocarbon-based Semi-II IPN Elastomers by High-energy Radiation Methods

J.D. Lipko, et al.: ibid., 23, (9) 2739 (1979)

$20911 \gamma$ Radiolysis of Cellulose Acetate S.M. Ali, et al.: ibid., 23, (10) 2893 (1979)

20912 Elastomeric Electron Beam-cured Coatings: Structure-property Relationships. I. Oligomer Structure

W. Oraby, et al.: ibid., 23, (11) 3227 (1979)

20913 Elastomeric Electron Beam-cured Coatings: Structure-Property Relationships. II. Chain Transfer Agents

W. Oraby, et al. ibid., 23, (11) 3243 (1979)

20914 Cast and Mold Polymerization of Organic Glass by Irradiation from Fluid and Soft Gel Prepolymers

H. Okubo, et al.: ibid., 24, (1) 161 (1979)

20915 New Coating Materials and Their Preparation by Radiation Polymerization. III. Antifogging Coating Composition

I. Kaetsu, et al.: ibid., 24, (1) 235 (1979)

20916 Degradation of Polystyrene by Gamma Irradiation: Effect of Air on the Radiationinduced Changes in Mechanical and Molecular Properties

T.N. Bowner, et al.: ibid., 24, (2) 425 (1979)

20917 Radiation-induced Polymerization of Ethylene in a Pilot Plant. I. Bulk Process

M. Takehisa, et al.: ibid., 24, (3) 853 (1979)

20918 Radiation-induced Polymerization of Ethylene in a Pilot Plant. II. Development of Wet-Wall Process

M. Takehisa, et al.: ibid., 24, (3) 865 (1979)

20919 Radiation-induced Copolymerization of $\alpha, \beta, \beta$-trifluoroacrylonitrile with $\alpha$-olefin

O. Matsuda, et al.: ibid., 24, (4) 1053 (1979)

20920 Gamma Radiation-induced Graft Copolymerization of Divinylbenzene onto Cellulose Fabric

S. Trobojević-Gobac, et al.: ibid., 24, (4) 1101 (1979)

20921 Preparation of Fresnel Lenses by Radiation Cast Polymerization

I. Kaetsu, et al.: ibid., 24, (6) 1515 (1979)

20922 Synthesis of Cationic Flocculant by Radiation-induced Copolymerization of Methyl 


\section{理工学文献題目集}

Chloride Salt of N, N-dimethylaminoethyl Methacrylate with Acrylamide in Aqueous Solution

T. Okada, et al.: ibid., 24, (7) 1713 (1979)

20923 Radiation-induced Polymerization of Ethylene in Pilot Plant. III. Heavy-phase Recycling Process

M. Takehisa, et al.: ibid., 24, (8) 1831 (1979)

20924 Statistical Analysis of Nitrogen-containing Vinyl-copolymers: Radiation-induced Copolymerization of Vinyl Acetate and $\mathrm{N}$ vinyl-2-pyrrolidone

N.A. Peppas, et al.: ibid., 24, (10) 2159 (1979)

20925 Radiation-modified Atactic Polypropylene as a Sensitizer for Photodegradation of Polyethylene

H. Omichi, et al.: ibid., 24, (11) 2311 (1979)

20926 Radiation Degradation of Polystyrene/

Poly(methyl Methacrylate) Blends

R.W. Garrett, et al.: ibid., 24, (12) 2415 (1979)

20927 Blood-compatibility-Water-content Relationships for Radiation-grafted Hydrogels B.D. Ratner, et al.: J. Polymer Sci. Polymer Symp., 66, 363 (1979)

20928 Radiation-induced Modification of Polyurethane-elastomers with Hydroxyethyl Methacrylate

B. Jansen, et al.: ibid., 66, 465 (1979)

$$
\text { (3.5) そ の 他 }
$$

20929 Radiation Sterilization of Triple Sugar Iron Agar

G. Altmann, et al.: Intern. J. Appl. Rad.

\& Isotopes, 30, (9) 527 (1979)

$$
\begin{aligned}
& \text { （4）トレーサ利用 } \\
& \text { (4・1）物理的トレーサ }
\end{aligned}
$$

20930 Apparent and Actual ${ }^{14} \mathrm{C}$ Retention in the Slower Turnover Bicarbonate Pool in Man when Using Liquid Scintillation Counting

M.B. Clague, et al.: Intern. J. Appl. \& Isotopes, 30, (10) 647 (1979)

20931 The Numerical Inverse Convolution Operation Combined with Spline FunctionsA New Effective Method for the Evaluation of Tracer Investigations in Flow Systems R. Nieswand, et al.: Isotopenpraxis, 16, (4) 105 08 (1980)

20932 On the Determination of the Partici- pation of Labelled Components of Lubricants in the Lamination on Friction Parts

K. Wagner, et al.: ibid., 16, (4) 112 17 (1980)

\section{（4·2） 化学的トレーサ}

20933 Radiometric Determination of Ion Mobility

R. Dreyer, et al.: Isotopenpraxis, 16, (4) 117 $\sim 19$ (1980)

$$
\text { （4·3） アクチバブルトレーサ }
$$

20864 (p. 2067, 左)

$$
\text { (4.4) その他 }
$$

20934 Intestinal Absorption of Magnesium in Man

P. Roth, et al.: Intern. J. Appl. Rad. \& Isotopes, 30, (9) 523 (1979)

20935 Mating Assessment of the Onion Fly Hylemya antiqua Meigen and the House Fly Musca domestica L. Using ${ }^{32} \mathrm{P}$

D.H. Ketel, et al.: ibid., 30, (10) 651 (1979)

20936 Universal Injection Appliance for Industrial Investigations with Liquid or Gaseous Tracers

M. Richter, et al.: Isotopenpraxis, 16, (3) 94 98 (1980)

\section{（5）分 析 \\ (5・1）放射化分析}

20937 Determination of Impurities in Aluminum Metals by Proton Activation

S. Shibata, et al.: Intern. J. Appl. Rad. \& Isotopes, 30, (9) 563 (1979)

20938 Determination of Selenium in Urine by Neutron Activation Analysis

R. Weingarten, et al.: ibid., 30, (10) 585(1979)

20939 A Cyclic Activation Method of Determining Short Half-lives

F. Özek, et al.: ibid., 30, (11) 715 (1979)

20940 Production of ${ }^{109} \mathrm{Cd}$ in Nuclear Reactors by Neutron Irradiation of Silver

N.N. Krasnov, et al.: ibid., 30, (12) 783 (1979)

20941 Activation Analysis of Carbon in Silicon by ${ }^{3} \mathrm{He}$ Ions in Comparison with Deuterons M.L. Boettger, et al.: Isotopenpraxis, 16, (4) $124 \sim 26$ (1980) 


\section{理工学文献題目集}

20942 Instrumental Neutron-activation Analysis of Submilligram Amounts of Geochemical Samples

V.I. Drynkin, et al.: Soviet Atomic Energy, 47, (1) 534 (1979)

20864 (p. 2067, 左)

\section{（5.2）放射化学的分析}

20943 Determination of Pertechnetate in Radiopharmaceuticals by High-pressure Liquid, Thin-layer and Paper Chromatography C.D. Russell, et al.: Intern. J. Appl. Rad. \& Isotopes, 30, (12) 753 (1979)

20944 Radiochemical Determination of the Dissolution Rate of Phosphate Coatings on Steel during the Anodic Electro-deposition of Paint Films

G. Reinhard, et al.: Isotopenpraxis, 16, (4) 108 12 (1980)

20864 (p. 2067, 左) 20933 (p. 2070, 右)

\section{（6）測定および測定機器}

\section{（6・1） 測 定 法}

20945 Factors Altering Optimum Liquid Scintillation Counting of ${ }^{3} \mathrm{H}$ or ${ }^{14} \mathrm{C}$ Amino Acids J. Farjanel, et al.: Intern. J. Appl. Rad. \& Isotopes, 30, (9) 537 (1979)

20946 Thermal Neutron Detection by Activation of $\mathrm{CaSO}_{4}: \mathrm{Dy}+\mathrm{KBr}$ Thermoluminescent Phosphors

A.M.P.L. Gordon, et al.: ibid., 30, (9) 571 (1979)

20947 An Inexpensive Method for the Acquisition of External Standard Quench Correction Capability

G.D. Nadkarni, et al.: ibid., 30, (11) 657 (1979)

20948 Untersuchungen zur Biokinetik von ${ }^{201} \mathrm{Tl}$ und ${ }^{99 m}$ Tc Zinn-Pyrophosphat beim Experimentellen Myokardinfarkt (EMI) der Katze H. Schön, et al.: ibid., 30, (11) 687 (1979)

20949 Tritium Counting Efficiencies and Time Stabilities of Samples with Different Amounts of Aqueous Salt Solutions in a Triton X-100 Toluene Scintillant

V. Zarybnicky, et al.: ibid., 30, (12) 729 (1979)

20950 Analyse des caractéristiques de la technique d'autoradiographies á haut pouvoir de résolution sur lames minces
G.V. Prabhu Gaunkar, et al.: ibid., 30, (12) 761 (1979)

20951 Copper as an Activation Detector for Thermal Neutron Fluence Measurements H.K. Kundu, et al.: ibid., 30, (12) 785 (1979)

20952 Rapid Method of Checking the Eluate of ${ }^{99} \mathrm{Mo} /{ }^{99 m} \mathrm{Tc}$ Generators for Impurities

P. Kleinert, et al.: Isotopenpraxis, 16, (3) 92 94 (1980)

20953 Some Experiences in Constructing the Photoefficiency Function of Ge-Gammadetectors for Radioanalytical Purposes

W. Goerner, et al.: ibid., 16, (4) 127 32 (1980)

20954 The Background in $\beta, \gamma$-coincidence Spectroscopy

S. Niese: ibid., 16, (4) 133 35 (1980)

20955 Efficiency Calibration of Germaniumspectrometers in the Energy Range from 122 $\sim 412 \mathrm{keV}$

U. Schötzig, et al.: Nucl. Instr. \& Methods, 169, (1) 43 (1980)

20956 A Calorimeter to Study Cosmic Ray Muon Interactions

K. Mitsui, et al.: ibid., 169, (1) 97 (1980)

20957 High Precision Time-of-flight Measurements of Neutron Resonance Energies in Carbon and Oxygen between 3 and $30 \mathrm{MeV}$

S. Cierjacks, et al.: ibid., 169, (1) 185 (1980)

20958 The Use of Logarithmic Pulse Height and Energy Scales in Organic Scintillator Spectroscopy

S. Whittlestone: ibid., 169, (1) 215 (1980)

20886 (p. 2068, 左)

\section{$(6 \cdot 2)$ 検 出 部}

20959 Comparison of $\mathrm{CaF}_{2}$ and LiF Measurements of Energy Deposition Rates in Materials Irradiated in a Large ${ }^{60} \mathrm{Co}$ Facility M.L. Dhawan, et al.: Intern. J. Appl. Rad. \& Isotopes, 30, (11) 677 (1979)

20960 Scatter Effects in Electron Dosimetry B.L. Gupta, et al.: ibid., 31, (1) 41 (1980)

20961 A Small Size Low-level Needle Counter

N. Takano, et al.: ibid., 31, (1) 61 (1980)

20962 An Investigation of the High Energy Dependence of LiF Dosemeters in Low Z Media

O.T. Ogunleye, et al.: ibid., 31, (1) 63 (1980) 20963 Optimizing the Energy Resolution of 


\section{理工学文献題目集}

Scintillation Counters at High Energies

H. Schölermann, et al.: Nucl. Instr. \& Methods, 169, (1) 25 (1980)

20964 Extruded Polystyrene, a New Scintillator J.C. Thevenin, et al.: ibid., 169, (1) 53 (1980)

20965 New Low Cost Acrylic Scintillators

C. Aurouet, et al.: ibid., 169, (1) 57 (1980)

20966 Proportional Counter Telescopes for Fast Neutron Spectrometry

H. Borst: ibid., 169, (1) 69 (1980)

20967 Response Functions of Spherically

Moderated Neutron Detectors

M.P. Dhairyawan, et al.: ibid., 169, (1) 115 (1980)

20968 Ionization Discrimination in Heliumoxygen Spark Chambers

M.J. Ashburn, et al.: ibid., 169, (1) 121(1980)

20969 A Proposal: Dynamic RAMs as Particle Detectors

G. Cerofolini, et al.: ibid., 169, (1) 125 (1980)

$20970 \gamma$-Ray Recording Efficiency of a Spherical

Detector

D.I. Konstantinov: Soviet Atomic Energy, 47, (1) 546 (1979)

\section{(6·3) 測定機器}

20971 Improving the Electric Field Uniformity in Large Hybrid Focal Plane Detectors

D. Shapira, et al.: Nucl. Instr. \& Methods, 169, (1) 77 (1980)

20972 A Balloon-borne $\mathrm{Ge}(\mathrm{Li})$ Spectrometer for Observation of Cyclotron Line Emissions from Neutron Stars

M. Yoshimori, et al.: ibid., 169, (1) 227 (1980)

20973 The Combination of Laser Micro-boring and High Resolution $\alpha$-spectroscopy for the Analysis of $\alpha$-emitting Isotopes in Irradiated High-temperature-reactor Fuel

M. Helmbold, et al.: ibid., 169, (1) 235 (1980)

20974 A Calorimeter for Measuring Local Electron-beam Absorbed Doses

V.A. Berlyand, et al.: Soviet Atomic Energy, 47, (1) 554 (1979)

20975 A Cadmium-sulfide $\gamma$-ray Dosimeter with Elevated Stability under Irradiation

V.K. Dubovói: ibid., 47, (1) 564 (1979)

20976 Principles of Construction of Crystal Coordinate Detectors for Nuclear Radiation B.M. Lebed', et al.: ibid., 47, (2) 622 (1979)

$$
\text { (6.4) そ の 他 }
$$

20977 Anomalous Intensity Variation of Backscattered Gamma Ray Peaks

K. Gopala, et al.: Nucl. Instr. \& Methods, 169, (1) 219 (1980)

20978 Rate Dependence of Counting Losses in Neutron Time-of-flight Measurements M.S. Moore: ibid., 169, (1) 245 (1980)

20979 Calculation of Parameters of Scintillation Detectors for Low-activity $\gamma$-rays

I.F. Lukashin: Soviet Atomic Energy, 47, (2) 641 (1979)

\section{（7）同位体の製造・分離 \\ （7・1）製造・分離・精製}

20980 A ${ }^{62} \mathrm{Cu}$ Generator

M. Yagi, et al.: Intern. Appl. Rad. \& Isotopes, 30, (9) 569 (1979)

20981 Investigation of the Preparation of ${ }^{97} \mathrm{Ru}$

M. Gessner, et al.: ibid., 30, (9) 578 (1979)

$20982{ }^{3} \mathrm{He}$ Bombardment of Manganese for the Production of ${ }^{55} \mathrm{Co}$

M. Watanabe, et al.: ibid., 30, (10) 625 (1979) 20983 The Production of Xenon Isotopes with Protons of Energies from 320 to $590 \mathrm{MeV}$ N.F. Peek, et al.: ibid., 30, (10) 631 (1979)

20984 Production of ${ }^{199} \mathrm{Tl}$ by Alpha Bombardment of Gold

Y. Nagame, et al.: ibid., 30, (11) 669 (1979)

20985 Isotope Separation by Laser Photochemistry in Nozzle Flows with Heterogeneous Condensation

P. Mathieu: ibid., 30, (12) 781 (1979)

20986 Cyclotron Isotopes and Radiopharmaceuticals-XXX. Aspects of Production, Elution and Automation of ${ }^{81} \mathrm{Rb}-{ }^{81 m} \mathrm{Kr}$ Generators T.J. Ruth, et al.: ibid., 31, (1) 51 (1980)

20987 Rapid Separation of Isobar Nuclides of Alkali and Alkaline Earth Elements by Use of a Surface Ion Source

H.-D. Schmick, et al.: Nucl. Instr. \& Methods, 169, (1) 139 (1980)

20988 Production of ${ }^{109} \mathrm{Cd}$ by Irradiation ${ }^{107} \mathrm{Ag}$ with Reactor Neutrons

A.G. Beda, et al.: Soviet Atomic Energy, 47, (2) 626 (1979)

20989 Vacuum Fission Chambers for Neutron Monitoring

A.B. Dmitriev, et al.: ibid., 47, (2) 636(1979) 


\section{$\mathrm{RI}$ 農学・生物学利用文献集 (7)}

農生文献トピックス

\section{${ }^{13} \mathrm{C}-\mathrm{NMR}$ による生合成研究}

$$
\text { 瀬 戸 治 男 }
$$

天然有機化合物の生合成研究には現在, ${ }^{13} \mathrm{C}-\mathrm{NMR} か ゙$ 広く利用されており ${ }^{1)}$ ，特に ${ }^{13} \mathrm{C}-{ }^{13} \mathrm{C}$ スピン結合を利 用した研究法 ${ }^{2}$ は, 他の手段では得られない炭素骨格 の生成機構に関する情報を提供する点できわめて重要 である。炭素以外の生体成分原子のトレーサーの検出 には, ${ }^{2} \mathrm{H}-,{ }^{15} \mathrm{~N}-\mathrm{NMR}$ 等によって直接トレーサーの核 を観測する方法もあるが，シグナルの分離が良くない $\left({ }^{2} \mathrm{H}-\mathrm{NMR}\right)$ ，核スピンをもたぬため NMR で検出でき ない $\left({ }^{18} \mathrm{O}\right)$, 測定感度が悪い $\left({ }^{15} \mathrm{~N}-\mathrm{NMR}\right)$ 等の欠点が 指摘されている。

これらの原子が ${ }^{13} \mathrm{C}$ と直接結合すると, ${ }^{13} \mathrm{C}-\mathrm{NMR} の$ シグナルに，(1)スピン結合による分裂，(2)緩和時間が 長くなるためのシグナル強度の減少，(3)高磁場側への シフト等の変化が生ずる。この現象を利用すれば，シ グナルの分離が良く, 感度も比較的良好な ${ }^{13} \mathrm{C}-\mathrm{NMR}$ よって, 研究対象化合物中に存在する水素, 酸素, 窒素 等のトレーサーの位置を決定することが可能になる。

Aspergillus parasiticus の代謝産物であるアベルフ ィン(1)（図1）には7 個の酸素原子が含まれている。 Vederas $ら^{3)}$ は $\left[{ }^{18} \mathrm{O}\right]$ ガスで標識した(1)を調製し, ${ }^{13} \mathrm{C}-\mathrm{NMR}$ 測定した結果, C-10シグナルのみが ${ }^{13} \mathrm{C}-{ }^{18} \mathrm{O}$ 結合のために高磁場側へシフトしていることを見出し た。一方, $\mathrm{CH}_{3}{ }^{18} \mathrm{C}^{18} \mathrm{O}_{2} \mathrm{H}$ で標識した(1)のスペクトル では, C-10 以外の酸素と結合したすべての炭素シグ ナルについて同じ現象が認められた。これらの実験に より, 酸素原子の(1)への取込みパターンは図1のよう に決定された。

カビ (Nectria coccinea) によって生産される抗生物 質であるアスコクロリン(4)（図 2 ）のトリプレニル部

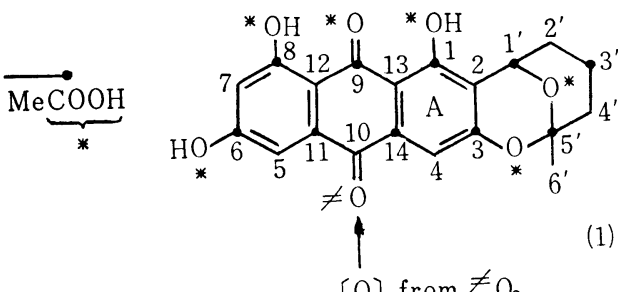

[O] from $\neq \mathrm{O}_{2}$
分は, エポキシド中間体(2)から，(3)に示す水素の転位 反応を経て生合成されると説明されている。 Hunter ら ${ }^{4)}$ は $\left[3^{-13} \mathrm{C}, 4-^{2} \mathrm{H}\right]$ メバラクトンを合成し，(4)を 標識した。得られたスペクトルでは, C-1 および C-5 シグナルに, ${ }^{2} \mathrm{H}$ と結合したための特徵的な变化が見 られた。この事実は，メバロン酸の4-位の水素が生合 成の途中で, 隣接する炭素 (メバロン酸のC-3に由来) に転位したことを示しており，図 2 の生合成経路の妥 当性を支持する有力な証拠となった。彼らは同じ前駆 体を利用してテルペン化合物であるフシコッシンの生 合成機構を巧みに解明している

同種の実験として， $\left[2-^{13} \mathrm{C}, 2-{ }^{2} \mathrm{H}_{3}\right]$ 酢酸を使ったポ リケタイド物質（シタロン，ルグロシン，2-ヘキシル -5ープロピルレゾルシノール) の生合成が三川ら つて報告されている。

一方, Barber $5^{7)}$ は, ${ }^{13} \mathrm{CH}_{3}{ }^{13} \mathrm{CO}_{2} \mathrm{H}$ を使う標識実験 に際して，重水を用いて培地を調製し，前駆体中に含 まれる軽水素をトレーサーとして利用する方法を提唱 している。ただし，高濃度の重水は微生物に毒性を示 すことが多いので, この方法は一般性に欠けるららみ がある。

${ }^{13} \mathrm{C}-{ }^{-15} \mathrm{~N}$ スピン結合を利用したものとして，ポーフ ィリン生合成の中間体 ${ }^{8)}$, 二ボマイシンの生合成 ${ }^{9)}$ 関する研究があげられる。このよらな ${ }^{13} \mathrm{C}-\mathrm{NMR}$ 利用 した他の核種のトレーサーを検出する方法は，反応機 構の詳細な研究にはきわめて有力であり，これからま すます多用されていくものと思われる。

\section{文献}

1) M. Tanabe: Biosynthesis 2, 241 (1973); 3, 247 (1975); 4, 204 (1976)

2) H. Seto, et al.: J. Amer. Chem. Soc., 95, 8461 (1973)

3) J.C. Vederas and T.T. Nakashima: J.C.S. Chem. Comm., 1980, 183 (1980)

4) R. Hunter and G. Mellows: Tetrahedron Lett., 1978, 5051 (1978)

5) A. Banerji, et al.: J.C.S. Chem. Comm., 1978, 843 (1978)

6) U. Sankawa, et al.: Tetrahedron Lett., 1978, 3375 (1978)

7) J. Barber and J. Staunton: J.C.S. Chem. Comm., 1979, 1098 (1979)

8) G. Burton, et al.: J. Amer. Chem. Soc., 101, 3114 (1979)

9) A.M. Nadzan and K.L. Rinehart, Jr.: ibid., 99, 4647 (1977)

図 1

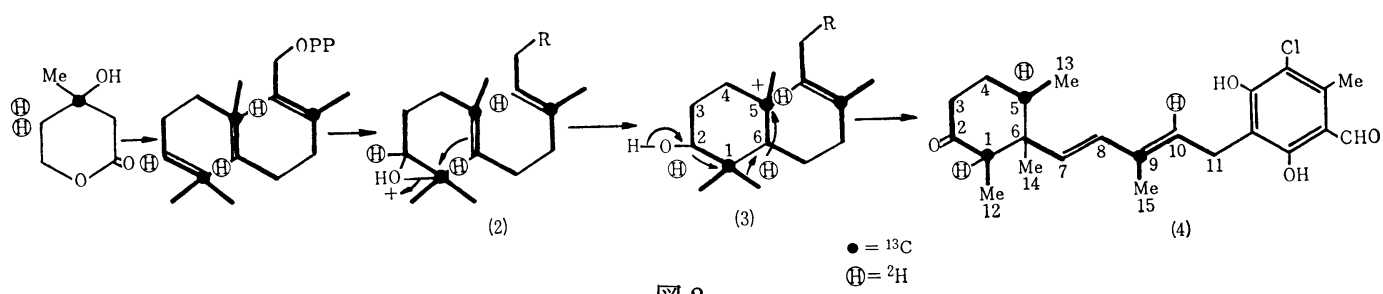

図 2 


\section{[1]微 生 物}

00552 Localization of Active Microorganisms in Cheese by Auto Radiography

Reyrolle, J., et al.: Appl. Environ. Microbiol., 38, (6) 1162 65 (1979) EN bacteria Camembert cheese ripening [microorganisms-unspecified, bacteria-unspecified] 69057460

00553 Stoichiometry and Stereochemistry of Deuterium Incorporated into Fattyacids by Cells of Escherichia coli Grown on Tritium Labeled Acetate

White, R.H.: Biochemistry, 19, (1) 9 15 (1980) EN Corynebacterium diphtheriae, malonyl coenzyme A, NADPH [Enterobacteriaceae, Coryneform group of bacteria] 69067129

00554 The Nature of the Damage to Escherichia coli DNA Induced by Gamma Irradiation

Bresler, S.E., et al.: Int. J. Radiat. Biol. Relat. Stud. Phys. Chem. Med., 36, (3) 289 300(1979) EN Col E1 plasmid, N-glycosidase, repair, endo nuclease [Enterobacteriaceae] 69067158

00654 (p. 60, 右) 00628 (p. 58, 右)

\section{[2]植物}

00555 Effect of Gamma-rays and 2,4-D on Germination Growth and Morphogenetic Responses in Guizotia abyssinica

Chopra, S., et al.: phytomorphology, 28, (1) 82 $\sim 87$ (1978) EN [Compositae] 69074269

00556 Biosynthesis of Triterpenoids from Amino Acids in Pisum sativum the Distribution of the Radioactivity in Squalene Biosynthesized from Radio Isotopically Labeled L-Leucine and L-Valine

Suga, T., et al.: phytochemistry, 19, (1) $67 \sim 70$ (1980) EN beta amyrin, squalene [Leguminosae] 69074330

00557 The Number of Chlorophyll-less Spots as a Criterion of Cyto Genetic Damage in
Soybeans Following Fast Neutron Treatments of Seeds

Muszynski, S., et al.: Bull. Acad. Pol. Sci. Ser. Sci. Biol., 27, (4) 245 50 (1979) EN cultivars caloria, chabarovska fiskeby S-703 R-11. 17 warszawska, cyclotron, impulse reactor [Leguminosae] 69074125

00632 (p. 58, 左) 00652 (p. 59, 左)

$$
\text { [3] 動 物 }
$$

00558 Regulation of Leishmania Populations within the Host 4. Parasite and Host Cell Kinetics Studied by Radioisotope Labeling Bradley, D.J.: Acta Trop., 36, (2) 171 80 (1979) EN mouse mononuclear phagocytes [Flagellata, Muridae] 69032241

00559 Some Radiobiological Consequences of Mycoplasma Contamination of Mammalian Cells in Tissue Culture

Cullen, B.M., et al.: Br. J. Radiol., 52, (622) 822 25 (1979) EN mouse ehrlich ascites, carcinoma, arginine concentration [mycoplasmas-unspecified, Muridae] 69047648

00560 RNA Synthesis during Ilyanassa obsoleta Oogenesis an Auto Radiographic Study

McCann-Collier, M.: Dev. Growth Differ., 21, (5) $391 \sim 400$ (1979) EN ribosomal synthesis, chromatin transcription, light microscopy [Gastropoda] 69051377

00561 Mathematical Modeling of Isotope Distribution in Animal Viscera

Belyaev, V.I., et al.: Dokl. Akad. Nauk. Ukr. S.S.R. Ser. B. Geol. Khim. Biol. Nauki., 0, (3) 234 37 (1979) RU fish [animalia-unspecified, Osteichthyes] 69054190

00562 Recovery Course in Mouse Spleen and Bone Marrow after Continuous Irradiation Mackova, N., et al.: Folia. Haematol. (Leipz.), 106, (3) $351 \sim 57$ (1979) EN radiation injury [Muridae] 69040470

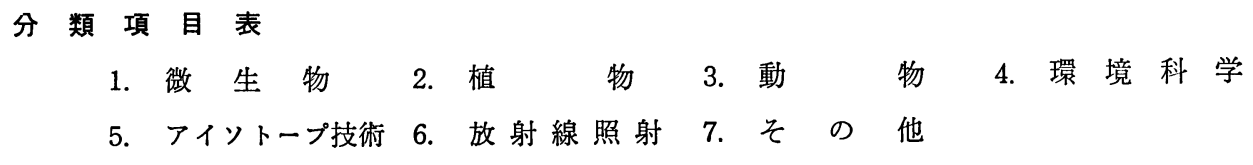
1. 微 生 物
2. 植
物
3. 動
物
4. 環 境 科学
6. 放 射 線 照 射
7. そ 他 
農学・生物学文献題目集

00563 Absence of Ecotropic or Recombinant Murine Leukemia Virus in Preleukemic and Leukemic X Irradiated NZB Mice

Harvey, J.J., et al.: Int. J. Cancer, 24, (3) 373 $\sim 76$ (1979) EN oncornavirus rat, sarcoma xc cell [Retroviridae-Oncovirinae, Muridae] 69045371

00564 Theory of Hyperfine Fields at ${ }^{57} \mathrm{Fe}$ and ${ }^{14} \mathrm{~N}$ Sites in Met-myo-globin and Related Compounds

Mun, S.K., et al.: J. Am. Chem. Soc., 101, (19) 5562 69 (1979) EN fluoro-myo-globin, fluoro-heme-pyridine,moessbauer spectroscopy, electron-nuclear double resonance spectroscopy 69014262

$00565{ }^{15} \mathrm{~N}$ Utilization and Microbial Protein Synthesis in the Rumen of Urea Fed Cattle

Borhami, B.E.A., et al.: J. Anim. Sci., 49, (5) 1306 11 (1979) EN friesian, bacteria, protozoa, fiber, diet, ATP, fatty-acid [microorganism sunspecified, bacteria-unspecified, protozoaunspecified, Bovidae] 69048312

00566 Calmodulin Development and Application of a Sensitive Radioimmunoassay Chafouleas, J.G., et al.: J. Biol. Chem., 254, (20) 10262 67 (1979) EN Renilla reniformis, Arachis hypogaea, Dictyostelium discoideum, Chlamydomonas reinhardii, bovine brain, rat testis muscle, cyclic nucleotide, phospho diesterase, parv albumin, troponin $\mathrm{C}$, calcium, binding protein, amino-acid sequence, immunological cross reactivity, ${ }^{125} \mathrm{I}$, bolton hunter procedure [Chlorophyta, Myxophyta, Leguminosae, Flagellata, Sarcodina, Cnidaria, Bovidae, Muridae] 69041528

00567 Physical Properties of the Detergent Extracted Nerve Growth Factor Receptor of Sympathetic Ganglia

Costrini, N.V., et al.: ibid., 254, (22) 11242 46 (1979) EN rabbit microsomes, molecular weight, triton $\mathrm{X}-100$, sodium deoxy cholate, chromatography, ultra centrifugation, deuterium labeled water [Leporidae] 69045787

00568 Auto Radiographic Identification of Acetyl Choline in the Rabbit Retina Masland, R.H., et al.: J. Cell. Biol., 83, (1) 159 $\sim 78$ (1979) EN neuron, amacrine cell, photoreceptor, ganglion phospholipid pathway, tritium labeling [Leporidae] 69033008
00569 Metabolism of ${ }^{14} \mathrm{C}$ Labeled Penfluron in the House Fly Musca domestica

Chang, S. C., et al.: J. Econ. Entomol., 72, (4) 482 85 (1979) EN chemosterilant, conjugated metabolites excreta [Diptera] 69037733

00570 Laboratory Studies of Sterility and Competitiveness of Boll Weevils Anthonomus-grandis-grandis Irradiated in an Atmosphere of Nitrogen Carbon dioxide or Air

Earle, N.W., et al.: ibid., 72, (5) 687 91 (1979) EN fertility, recovery, gamma irradiation, testes [Coleoptera] 69036192

00571 Mitotic Abnormalities in Sea-urchin Clypeaster japonicus Embryos during the Early Cleavage Stages Induced by UV Irradiation of Sperm

Ejima, Y., et al.: J. Fac. Sci. Univ. Tokyo Sect. IV. Zool., 14, (2) 177 90 (1978) EN sperm, bridged chromosome, mazia method [Echinoidea] 69029890

00572 Morphological Abnormalities in Seaurchin Pseudocentrotus depressus Embryos Induced by UV Irradiation of Sperm Ejima, Y.: ibid., 14, (2) 191 200 (1978) EN blastula gastrula pluteus, development, abortiveness, dose response [Echinoidea] 69029891

00573 Differentiating the Life Stages of the Southern Pine Beetle Dendroctonus frontalis from Radiographs

Mizell, R.F. III., et al.: J. Ga. Entomol. Soc., 14, (3) 229 38 (1979) EN pine bark [Coniferopsida (Coniferae), Coleoptera] 69015552

00574 Measurement of Cell Mediated Inflammation in Experimental Murine Auto Immune Encephalo Myelitis by Radio Isotopic Labeling

Linthicum, D.S., et al.: J. Immunol., 123, (4) 1799 805 (1979) EN spinal cord, myelin, basic protein [Muridae] 69037472

00575 Regulation of the Murine Immuno Globulin E Antibody Response 1. Characterization of Suppressor Cells Regulating Persistent and Transient Responses and their Sensitivity to Low Doses of X Irradiation

Schwenk, R.J., et al.: ibid., 123, (6) 2791 98 (1979) EN [Muridae] 69044500

00576 Isotopic Labeling of DNA in Rat Adi- 
pose Tissue Evidence for Proliferating Cells Associated with Mature Adipocytes Klyde, B.J., et al.: J. Lipid. Res., 20, (6) 691 $\sim 704$ (1979) EN adipocyte, progenitor, collagenase, Dnase tritiated thymidine [Muridae] 69014461

00577 Protective Effect of Saccharides on Radiation Induced Hemolysis of Rabbit Erythrocytes

Sasa, M.: J. Kansai Med. Univ., 30, (3) 461 72 (1978) JA glucose, sucrose, galactose, radioprotectorant [Leporidae] 69033744

00578 The Subgenus Persicargas Ixodoidea Argasidae Argas 30. The Effect of Gamma Radiation on Fertility and Longevity of Adult Argas arboreus

Shanbaky, N.M., et al.: J. Med. Entomol., 16, (2) 116 20 (1979) EN oviposition, hatch, dominant, lethal [Acarina] 69029098

00579 Immunity to Carcinogen Induced Transplantable Fibro Sarcomas in B-2-B-2 Chickens 4. Effect of Whole Body Gamma Radiation on Localization and Growth of Intra Venously Injected Tumor Cells Palladino, M.A., et al.: J. Natl. Cancer Inst., 63, (3) 737 43 (1979) EN soybean trypsin inhibitor, propionibacterium-acnes, blood flow, vascular influences [Propionibacteriaceae, Leguminosae, Galliformes] 69031590

00580 Autoradiographic Analyses of the Cytokinetic Effects of Bleomycin on the Mouse Tumor

Fujimoto, J.: ibid., 63, (3) 769 74 (1979) EN fujimoto ascites cells, antineoplastic-drug, ${ }^{14} \mathrm{C}$ bleomycin, tritium labeled deoxythymidine, mitosis, cell cycle [Muridae] 69031785

00581 Partial Deletion of Chromosome 2 in Myelocytic Leukemias of Irradiated C-3HHe and RFM Mice

Hayata, I., et al.: ibid., 63, (3) 843 48 (1979)

EN banding techniques [Muridae] 69031333

00582 Synergism of DI Ethylstilbestrol and Radiation in Mammary Carcinogenesis in Female F-344 Rats

Holtzman, S., et al.: ibid., 63, (4) 1071 74 (1979) EN pituitary tumor, pyometritis, fibro adenoma [Muridae] 69031473

00583 Responses of Vibrissa Sensitive Cor- tical Neurons in Normal and Prenatally X-irradiated Rat

Ito, M., et al.: J. Neurophysiol., 42, (6) 1711 26 (1979) EN somato sensory cortex, gestation, vibrissal, sensory signals, spike stellate cells [Muridae] 69039118

00584 Discrepancies in the Extracellular Space of Sympathetic Ganglia Measured Using Different Isotopes of Mannitol and Sucrose

Garthwaite, J.: J. Neurosci. Methods, 1, (2) 185 94 (1979) EN rat superior cervical ganglia, tritium, ${ }^{14} \mathrm{C}$, thin layer chromatography, in vitro [Muridae] 69052407

00585 Effect of Food Intake on the Tissue Distribution of ${ }^{67} \mathrm{Ga}$, Concise Communication

Hayes, R.L., et al.: J. Nucl. Med., 20, (9) 938 $\sim 40$ (1979) EN mouse, rat, fasting [Muridae] 69026647

00586 A Study of the Relationship between Chemical Structure and Bone Localization of ${ }^{99 m}$ Tc-labeled Diphosphonic Acids, Concise Communication

Wang, T.S.T., et al.: ibid., 20, (10) 1066 70 (1979) EN rat, femur muscle, liver, methylene diphosphonic acid ethylidene, diphosphonic acid, benzylmethylene diphosphonic acid, isopropylidene diphosphonic acid, dichloromethylene diphosphonic acid, blood clearance [Muridae] 69021289

00587 Isolation and Characterization of Surface Antigens from Schistosoma mansoni 1. Evaluation of Techniques for Radio Isotope Labeling of Surface Proteins from Adult Worms

Hayunga, E.G., et al.: J. Parasitol., 65, (4) 488 〜96 (1979) EN mouse tegument membrane, molecular weight, electron microscopy, bolton hunter method, freeze thaw, lacto peroxidase, chloramine $\mathrm{T}$ iodo-sulfanilic-acid, ${ }^{125} \mathrm{I}$ electrophoresis, periodic-acid, schiff, coomassie blue staining [Trematoda, Muridae] 69030570

00588 Radiation Induced Biochemical Changes in the Larvae of House fly Musca domestica

Chander, L., et al.: J. Radiat. Res., 20, (2) 137 $\sim 45$ (1979) EN pupariation delay, glycogen free sugar, protein content, gamma irradiation [Diptera] 69033751 
岪学・生物学文献題目集

00589 Effect of Radiation on Fin Regeneration of the Fish Oryzias latipes with Special Reference to Dose Rate

Hama-Furukawa, A.: ibid., 20, (2) 215 24 (1979) EN cell differentiation, sparing effect [Osteichthyes] 69033752

00590 Effect of Ethanol on the Retention of ${ }^{241} \mathrm{Am}$ in the Baboon Liver

Cohen, N., et al.: J. Toxicol. Environ. Health, 4, (5/6) 825 34 (1978) EN metabolic-drug, liver bile, feces [Cercopithecidae] 69012937

00591 Incorporation of ${ }^{15} \mathrm{~N}$ Administered to Germ-free and Specific Pathogen-free Piglets AS ${ }^{15} \mathrm{~N}$ Urea into Amino-acids of $\mathrm{Hy}$ drolyzed Liver and Muscle Proteins

Deguchi, E., et al.: Jpn. J. Vet. Res., 26, (3/4) 68 73 (1978) EN bacterial urease, glutamicacid, histidine, threonine, trichloroacetic acid [bacteria-unspecified, Suidae] 69011402

00592 The Marrow Fat Cell Response to Xray Induced Aplasia in Rabbits

Bathija, A., et al.: Life Sci., 25, (11) 921 28 (1979) EN new-zealand rabbit, femur, ${ }^{14} \mathrm{C}$ labeled palmitate, peri nephritic fat hemopoietic proliferation [Leporidae] 69033742

$\begin{array}{llll}00601 & \text { (p. 55, 右) } & 00657 & \text { (p. 59, 右) } \\ 00608 & \text { (p. 56, 左) } & 00658 & \text { (p. 59, 右) } \\ 00631 & \text { (p. 58, 左) } & 00663 & \text { (p. 60, 左) } \\ 00635 & \text { (p. 58, 左) } & 00664 & \text { (p. 60, 左) } \\ 00643 & \text { (p. 58, 右) } & 00665 & \text { (p. 60, 左) } \\ 00644 & \text { (p. 58, 右) } & 00666 & \text { (p. 60, 左) } \\ 00645 & \text { (p. 58, 右) } & 00667 & \text { (p. 60, 右) }\end{array}$

\section{[4]環 境 科 学}

00593 Radio Carbon as a Tracer of Urban Pollution

Drndarski, N. D.: Glas. Khem. Drush. Beogr., 43, (9) 635 40 (1978) EN fuel carbon, industrial waste 69067945

00594 Pink Bollworm Pectinophora-gossypiella Radiation Sterility and Computer Simulation of Population Growth

Barlett, A.C., et al.: Southwest Entomol., 4,(3) 216 23 (1979) EN hexalure, traps reproductive, rates, California U.S.A. [Lepidoptera] 69063675

00595 Reduction of Radiation Induced Vitamin Losses by Irradiation of Foodstuffs at
Low Temperatures and by Exclusion of Atmospheric Oxygen

Diehl, J.-F.: Z. Lebensm-Unters.-Forsch., 169, (4) $276 \sim 80$ (1979) GE egg, powder, sunflower oil, oats, heat [Gramineae, Compositae] 69064280

00621 (p. 57, 左)

$$
\text { [5]アイソトープ技術 }
$$

$00596{ }^{13}$ C NMR Spectra of Phenolic Glycosides Isolated from Chestnut Galls Ozawa, T., et al.: Agric. Biol. Chem., 43, (6) 1173 78 (1979) [Fagaceae] 69019211

00597 Fluorographic Detection of Radioac. tivity in Poly Acrylamide Gels with the Water Soluble Fluor Sodium Salicylate Chamberlain, J.P.: Anal. Biochem., 98, (1) 132 \%35 (1979) EN diphenyloxazole 69012946

00598 Extraction and Measurement of Deuterium Oxide at Tracer Levels in Biological Fluids

Byers, F.M.: ibid., 98, (1) 208 13 (1979) EN IR-analysis [vertebrata-unspecified] 69014123

00599 The Synthesis of Radioactive 3-methylthiopropionate and Other Alkyl-thio Fatty Acids

Steele, R.D., et al.: ibid., 98, (2) 281 86 (1979) EN yeast, aldehyde dehydrogenase, mammalian methionine metabolism [fungi-unspecified, mammalia-unspecified and extinct] 69020945

00600 Scintillation Counting of Tritium Containing and ${ }^{14} \mathrm{C}$ Containing Gel Slices A 1 Step Method

Aloyo, V.J.: ibid., 99, (1) 161 64 (1979) EN poly acrylamide, heating oven 69040480

00601 An Improved Procedure for Solubilization and Assay of Blood and Feces in Liquid Scintillation Counting

Michaels, E.B., et al.: ibid., 99, (2) 288 96 (1979) EN rat, mouse, ammonium bicarbonate, triton $\mathrm{X}-100$, trypsin, peroxide, decolorization, tritium, dry oxidation, drug absorption, drug disposition [Muridae] 69054199

00602 Method for Quantitative Analysis of 16, 16-dimethyl Prostaglandin E-2 from Plasma Using Deuterium Labeled Carrier and Gas Chromatography Mass Spectro- 
農学・生物学文献題目集

metry

Steffenrud, S., et al.: ibid., 100, (1) $109 \sim 17$

(1979) EN [vertebrata-unspecified] 69043340

00603 Specific Tritium Labeling of Gamma Carboxy Glutamic-acid in Proteins

Hauschka, P.V.: Biochemistry, 18, (22) 4992 99 (1979) EN vitamin $\mathrm{K}$ dependent carboxylation 69034767

00604 Blood Sample ${ }^{59} \mathrm{Fe}$ to ${ }^{55} \mathrm{Fe}$ Activity Ratio Measurement Using a Semiconductor Detector

Kumpulainen, L.H., et al.: Int. J. Appl. $R a$ diat. Isot., 30, (7) 407 10 (1979) EN X-ray peak disturbing radionuclides [vertebrata-unspecified] 69021018

00605 Studies on the Radio Acetylation of Whole Cells in Culture

Gersten, D.M., et al.: ibid., 30, (8) 469 72 (1979) EN mouse, sheep, tumoricidal [Bovidae, Muridae] 69012944

$00606{ }^{71} \mathrm{Ga}$ and ${ }^{31} \mathrm{P}$ NMR Studies of the Interactions of Gallium with Phosphoricacid in Aqueous Solution

Lenkinski, R.E., et al.: J. Am. Chem. Soc., 100, (17) $5383 \sim 86$ (1978) EN mouse L-1210 leukemia cells, tumor scanning radio nuclides [Muridae] 69007292

00607 Automated Scanning of ${ }^{14} \mathrm{C}$ on Polyacrylamide Gel

Magnusson, R.P., et al.: J. Biochem. Biophys. Methods, 1, (1) 65 68 (1979) EN protein electrophoresis 69041475

00608 The Temperature Dependence of Computed Tomography Attenuation Values Bydder, G.M., et al.: J. Comput. Assist. Tomogr., 3, (4) 506 10 (1979) EN body tissue fluid [vertebrata-unspecified] 69054200

00609 A New Chromatographic Method Using Immobilized Acriflavine for Measuring Cyclic AMP in Cells Pre Labeled with Radioactive Adenine

Rochette-Egly, C., et al.: J. Cyclic Nucleotide Res., 5, (5) 397 406 (1979) EN rat [Muridae] 69041461

00610 A Radio Isotopic Technique for Measuring the Mononuclear Inflammatory Response in Sindbis Virus Induced
Encephalitis of Mice

Anders, E.M., et al.: J. Immunol. Methods, 29, (2) 167 72 (1979) EN arbovirus [Togaviridae, Muridae] 69007425

00611 Convenient Syntheses of Deuteriumlabeled Nicotine and Nicotine Analogs Seeman, J.I., et al.: J. Labelled Compd. $R a$ diopharm., 16, (3) 387 96 (1979) EN sodium cyano-borohydride, cyclic imine, lithium amide, deutero, iodo methylation [Solanaceae] 69025420

00612 Labeling of Neuroleptic Butyrophenones. 2. Synthesis of ${ }^{14} \mathrm{C}$-labeled 2'-amino4'-fluoro-4-4-hydroxy-4-3-trifluoromethylphenylpiperidino Butyrophenone

Nakatsuka, I., et al.: ibid., 16, (3) 407 14 (1979) EN neuroleptic cyclo propyl-2 4-difluorophenyl ketone carbonyl ${ }^{14} \mathrm{C}$ cyclo propanecarboxylic-acid M di fluoro benzene 4 chloro-2' 4'-difluoro butyrophenone 11 ethylenedioxy-12 4-difluorophenyl-4-4-hydroxy-4-3-trifluoro methylphenylpiperidino butane hydro chloricacid ketal piperidine benzylamine 69018788

$00613{ }^{11} \mathrm{C}$ labeled Octanal and Benzaldehyde

Tang, D.Y., et al.: ibid., 16, (3) 435 40 (1979) EN boro-bi-cyclo-3, 3, 1-nonane-phenyl-magnesium bromide, gas liquid pressure chromatography, toxicological inhalation studies 69027131

00614 Synthesis of ${ }^{14} \mathrm{C}$-labeled Haloperidol, Hexo-deuterated Haloperidol and Octadeuterated Haloperidol

Fellows, I., et al.: ibid., 16, (3) 449 62 (1979) EN neuroleptic metabolism, bio-availability, pharmaco kinetics 69018789

00615 Synthesis of Labeled Histamine ${ }^{2} \mathbf{H}$ Receptor Antagonists 1. Synthesis of Deuterium Sulfur and Tritium Labeled Cimetidine and Metiamide by Exchange Hesselbo, T., et al.: ibid., 16, (3) 463 72 (1979) EN 24 methyl-5-imidazolylmethyl thioethylamine, methyl isothio cyanate pyridine ${ }^{35} \mathrm{~S}$ ethanol, imidazole ring, pharmaco kinetics 69032472

00616 Labeled Organo-phosphorus Pesticides. 3. Synthesis of ${ }^{14} \mathrm{C}-$ labeled o-2, 6-dichloro-4-methylphenyl-o, o-dimethyl Phosphorothioate 
農学・生物学文献題目集

Yoshitake, A., et al.: ibid., 16, (3) 477 82 (1979)

EN fungicide metabolic studies [abstracts of mycology] 69020382

00617 The Synthesis of Deuterium-labeled Cholesterol

Gruenke, L.D., et al.: ibid., 16, (3) 495 500 (1979) EN cholesterol, 3, 4-deuterium-delta-4cholesten, 3-one-delta-4-cholesten, 3-one-2, 2, 4, 6,6 , deuterium-sodium borodeuteride, ethanol, sodium borohydride 69025422

00618 Preparation of the Radio-iodinated Histamine Amide of 4-o-Carboxypropyldiethyl Stilbestrol

Johnson, H.J.Jr., et al.: ibid., 16, (3) 501 06 (1979) EN carcinogen, radiation damage 69024382

00619 Evaluation and Application of Alumina Based ${ }^{82} \mathbf{R b}$ Generators Charged with High Levels of ${ }^{85} \mathbf{S r}$

Yano, Y., et al.: J. Nucl. Med., 20, (9) 961 66 (1979) EN potential myocardial blood flow imaging [vertebrata-unspecified] 69033762

00620 Radiolysis Products Analysis of Aqueous Thymine and Nitrous Oxide Solutions Idris, Ali.K.M., et al.: J. Radiat. Res., 20, (2) 146 56 (1979) EN hydroxy thyminyl radicals, ${ }^{60} \mathrm{Co}$ [organisms-unspecified] 69047302

00621 Radium Determination in Soil Samples Using a $\boldsymbol{\gamma}$-ray Coincidence Spectrometer

Prestwich, W.V., et al.: J. Radioanal. Chem., 50, (1/2) 249 60 (1979) EN natural radioactives 69026948

00622 Radioassay of Serum Vitamin B-12 Using a Competitive Protein Binding Technique

Lal, R., et al.: ibid., 52, (1) 21 30 (1979) EN egg yolk, binding protein [vertebrata-unspecified, Galliformes] 69048501

00623 Micro Analysis of Biometallic Compounds Using Nuclear and Atomic Activation

Stock, G.J. Jr., et al.: ibid., 52, (1) 117 26 (1979) EN alkaline phosphatase, amylase, carbonic anhydrase, diamine oxidase, myoglobin, vitamin B-12 69048481

00624 Simultaneous Determination of Uranium and Plutonium Isotopes in Soils by
Means of Single Alpha Spectrometry

Hashimoto, T., et al.: ibid., 52, (1) 133 42 (1979) EN ${ }^{230} \mathrm{U},{ }^{238} \mathrm{U},{ }^{234} \mathrm{U},{ }^{236} \mathrm{Pu},{ }^{239} \mathrm{Pu},{ }^{240} \mathrm{Pu}$, ${ }^{238} \mathrm{Pu} \quad 69054059$

00625 Spatial Resolution and Calibration Characteristics of 2 Narrow Probe $\boldsymbol{\gamma}$-ray Transmission Systems for the Measurement of Soil Bulk Density in situ Soane, B. D., et al.: J. Soil Sci., 30, (3) 517 28 (1979) EN 69054480

00626 Influence of Metallic Shields on Presumably Cosmic Radiation Affecting Surfaces of Nickel Plated Slides Used in Immunological Studies

Rothen, A.: Physiol. Chem. Phys., 11, (3) 193 ح204 (1979) EN antibody, radioprotectorant 69050891

$\begin{array}{llll}00552 & \text { (p. 52, 左 }) & 00574 & \text { (p. 53, 右 }) \\ 00558 & \text { (p. 52, 右 }) & 00580 & \text { (p. 54, 左) } \\ 00560 & \text { (p. 52, 右 }) & 00587 & \text { (p. 54, 右 }) \\ 00568 & \text { (p. 53, 左) } & & \end{array}$

\section{〔6〕放射線照射}

00627 Irradiation of Gut Associated Lymphoid Tissue and Immune Response of Guinea pig

Gupta, R.M., et al.: Indian J. Med. Res., 69, 1023 27 (1979) EN sheep erythrocyte, delayed hyper sensitivity, antibody production, bone marrow derived cell [Bovidae, Caviidae] 69058165

00628 Capacity of Irradiated Echinostome Sporocysts to Protect Schistosoma mansoni in Resistant Biomphalaria glabrata

Lie,K.J., et al.: Int. J. Parasitol., 9, (6) 539 44 (1979) EN echinostoma-lindoense, echinostomaliei, echinostoma-paraensei, miracidia puertorican strain, st-lucian strain [Trematoda, Gastropoda] 69058364

00629 Alkali Labile Sites and Post Irradiation Effects in Gamma Irradiated Biologically Active Double Stranded DNA in Aqueous Solution

Lafleur. M.V.M., et al.: Int. J. Radiat. Biol. Relat. Stud. Phys. Chem. Med., 36, (3) 241 48 (1979) EN bacteriophage phi-X-174 [Bacterial viruses] 69068740

00630 Effects of Varying Oxygen Concen- 
艇学・生物学文献題目集

tration on the X-ray Sensitivity of Transforming DNA

Held, K.D., et al.: Int. J. Radiat. Biol. Relat. Stud. Phys. Chem. Med., 36, (6) 613 20 (1979) EN Bacillus subtilis [Bacillaceae] 69064401

00631 Mutagenic Effect of Cyclophosphane on Bone Marrow Cells of Irradiated Rats Barkan, R.S., et al.: Genetika, 15, (5) 862 67 (1979) RU mutagen, X irradiation, gamma irradiation, chromosome aberrations [Muridae] 69057640

00632 Gamma Irradiated Plant Callus Tissue Cytokinins from Transfer RNA

Pandey, K.N., et al.: In Vitro (Rockville), 15, (11) 857 60 (1979) EN Haworthia mirabilis, tobacco, callus, cytokinin bioassay [Liliaceae, Solanaceae] 69060594

00633 Formation of Gamma Lactones and Delta Lactones in Irradiated Beef

Vajdi, M., et al.: J: Am. Oil Chem. Soc., 56, (10) 906 07 (1979) EN postulated mechanism [Bovidae] 69057502

00634 Fatty Acid Composition of Lipids and Cholesterol Content of Normal and Irradiated Rat Incisor Pulps

Ohashi, S.: Okayama Igakkai Zasshi, 91, (1/2) 229 40 (1979) JA palmitic acid, oleic acid, stearic acid, arachidonic acid, thin-layer chromatography, gaschromatography, whole body X-irradiation [Muridae] 6901.9961

00635 Changes in Cholesterol Content and Fatty Acid Composition of Serum Lipid in Irradiated Rats

Ohashi, S.: ibid., 91, (1/2) 241 50 (1979) JA liver, arachidonic acid, linoleic acid, steric acid, oleic acid [Muridae] 69026634

00636 Wholesomeness of Irradiated Cocoa Beans the Effect of Gamma Irradiation on the Chemical Constituents of Cocoa Beans Takyi, E.E.K., et al.: J. Agric. Food Chem., 27, (5) $979 \sim 82$ (1979) EN chromatography, fats, sterilization [Sterculiaceae] 69022971

00637 The Reduction of Met-hemerythrin by Hydrated Electron and Carbon Dioxide Anion from Pulse Radiolysis Studies Harrington, P.C., et al.: J. Biol. Chem., 254, (16) 7505 08 (1979) EN Phascolopsis gouldii, themiste-pyroides, iron center heme protein, reduction [Sipunculoidea] 69023875

00638 Reliability of the Tinplate Can for Packaging of Radappertized Beef under Production Conditions

Killoran, J.J., et al.: J. Food Process Preserv., 3, (1) 11 24 (1979) EN freezing, transport, storage [Bovidae] 69016154

00639 Reliability of Flexible Packaging of Radappertized Beef under Production Conditions

Killoran, J.J., et al.: ibid., 3, (1) 25 34 (1979) EN transportation, storage, wholesomeness [Bovidae] 69016155

00640 Experiences in the Operation of Food Irradiation Facilities

Gruenewald, T., et al.: ibid., 3, (1) 35 42 (1979)

EN electrons, X-rays, ${ }^{137} \mathrm{Cs},{ }^{60} \mathrm{Co} \quad 69016163$

00641 The National Food Irradiation Program Conducted by the U.S.A. Department of the Army

Brynjolfsson, A.: ibid., 3, (2) 125 38 (1979)

EN review 69043890

00642 Dosimetry in Support of Wholesomeness Studies

Jarrett, R.D., et al.: ibid., 3, (2) 145 76 (1979) EN large-scale processing irradiation sources 69043884

00643 Influence of Field Applications of Diflubenzuron on Longevity Fertility and Attractiveness of Released Irradiated Boll Weevils Anthonomus grandis grandis Mitchell, E.B., et al.: J. Ga. Entomol. Soc., 14, (3) 251 54 (1979) EN egg hatch [Coleoptera, abstracts of entomology] 69015535

00644 Effects of Neutron Radiation of Mouse Hair Matrix Cell Populations

Malkinson, F.D., et al.: J. Invest. Dermatol., 72, (6) 320 22 (1979) EN [Muridae] 69012919

00645 The Subgenus Persicargas Ixodoidea Argasidae Argas 32. Effect of Sub Sterilizing Doses of Gamma Radiation on Male Fertility and Progeny of Argas arboreus

Khalil, G.M., et al.: J. Med. Entomol., 16, (4) 339 42 (1979) EN sex ratio, fecundity, sex linked lethal genes, embryo death [Acarina] 69043234 
軠学・生物学文献題目集

00646 Effects of Low Level X-radiation on 7, 12-dimethyl Benz-a-anthracene-induced Lingual Tumors in Syrian Golden Hamsters

Lurie, A.G., et al.: J. Natl. Cancer Inst., 63, (1) $147 \sim 52$ (1979) EN carcinogen, papilloma [Cricetidae] 69017785

00647 Effect of Single and Fractionated Doses of Gamma Radiation on Pupariation of House Fly Musca domestica

Spinivasan, A., et al.: J. Radiat. Res., 20, (2) 157 65 (1979) EN sparing effect of dose fractionation, repair energy, metabolism inhibitors DNA binding agents protein synthesis inhibitors [Diptera] 69058290

00648 Chemical Changes in the Chloroform Paraffin System Irradiated by ${ }^{60} \mathrm{Co} \gamma$-rays 1. Examinations on Variable Factors Yoshino, T., et al.: ibid., 20, (2) 196 208 (1979) EN methyl yellow dosimeter phantom [organisms-unspecified] 69047317

00649 Ultrastructural Features of Spironucleosis Hexamitiasis in $\mathrm{X}$ Irradiated Rat Small Intestine

Gruber, H.E., et al.: Lab. Anim., 13, (3) 199 202 (1979) EN spironucleus-muris protozoa microorganism crypt lumina, micro villar border basement membrane mucous cell digestive vacuole paneth cell phagocytosis immuno suppression [microorganisms-unspecified, Flagellata, Sarcodina, Muridae] 69011487

00650 An Autoradiographic Study of Unscheduled DNA Synthesis in the Germ Cells of Male Mice Treated with X-rays and Methyl Methanesulfonate

Sotomayor, R.E., et al.: Mutat. Res., 62, (2) 293 310 (1979) EN type III elongating spermatid, round spermatid, spermatocyte [Muridae] 69023120

00651 Fate of Fragments and Properties of Translocations of Holo Kinetic Chromosomes after X irradiation of Mature Sperm of Tetranychus urticae Acari Tetranychidae Tempelaar, M.J.: ibid., 63, (2) 301 16 (1979) EN nonviable haploid, offspring, meiosis mitosis univalent, multivalent, mis segregation, recessive lethal infecundity [Acarina] 69050510

00652 Micro Nuclei Induced by X-rays and Chemical Mutagens in Meiotic Pollen
Mother Cells of Tradescantia paludosa, A Promising Mutagen Test System

Ma, T.-H.: ibid., 64, (5) 307 14 (1979) EN ethyl methanesulfonate sodium azide, hydrazoicacid, drug chemical safety evaluation [Commelinaceae] 69044090

00653 Mutagenic Cholesterol Preparations Smith, L.L., et al.: ibid., 68, (1) 23 30 (1979) EN Salmonella typhimurium, strains TA-1537, TA-1538, TA-78, autooxidation product, ${ }^{60} \mathrm{Co}$ gamma irradiation, heating [Enterobacteriaceael 69023012

00654 Use of Microcalorimetry for the Characterization of Microbial Activity in Soil Ljungholm, K., et al.: Oikos., 33, (1) 15 23 (1979) EN streptomycin, glucose, heat, actidione, carbon dioxide, oxygen, $\gamma$-irradiation, ampoul technique [microorganisms-unspecified] 69020215

00655 Vitamin E Induces Morphological Dif ferentiation and Increases the Effect of Ionizing Radiation on Neuroblastoma Cells in Culture

Prasad, K.N., et al.: Proc. Soc. Exp. Biol. Med., 161, (4) 570 73 (1979) EN mouse, NBP-2 cell, rat glioma C-6 cell, radiosensitizer, antineoplastic drug [Muridae] 69024752

00656 Effect of Cortisone and X-irradiation on Cellular Depletion and Regeneration in the Thymus of Mice, Experimental Dis crimination between Thymus Lymphocyte Precursors in the Bone Marrow and in the Thymus

Hiesche, K.D., et al.: Pathol. Res. Pract., 164, (2) $157 \sim 66$ (1979) EN hematologic drug [Muridae] 69021192

00657 Influence of Caffeine on Sparing Effect of Dose Fractionation in House Fly Larvae Srinivasan, A., et al.: Radiat. Environ. Biophys., 16, (2) 177 81 (1979) EN Musca domestica, radiosensitizer, ascorbic-acid, radioprotectorant, pupariation [plantae-unspecified Diptera] 69012917

00658 Long-term Effects of Negative Pions in Female Mice Exposed to Whole Body Irradiation

Zimmermann, A., et al.: ibid., 16, (3) 295 98 (1979) EN carcinogenesis, ovarian tumor, histopathology [Muridae] 69052026 
農学・生物学文献題目集

00659 Potentially Lethal Damage VS Sublethal Damage Independent Repair Processes in Actively Growing Chinese Hamster Cells

Utsumi, H., et al.: Radiat. Res., 77, (2) 346 60 (1979) EN lung V-79 cells, DNA osmotic effects, nuclear membrane, $\mathrm{X}$ irradiation [Cricetidae] 9012911

$00660{ }^{13}$ N Species Formed by Proton Irradiation of Water

Tilbury, R.S., et al.: ibid., 79, (1) 22 33 (1979) EN ${ }^{13} \mathrm{~N}$ labeling 69040478

00661 Excision of X-ray Induced Thymine Damage in Chromatin from Heated Cells Warters, R.L., et al.: ibid., 79, (1) 113 21 (1979) EN chinese hamster ovary cell, hyperthermia, DNA, excision enzyme, denaturation, radiosensitization [Cricetidae] 69023133

00662 Premature Chromosome Condensation Following $\mathrm{X}$-irradiation of Mammalian Cells, Expression Time and Dose Response Griffiths, T.D., et al.: ibid., 79, (1) 187 202 (1979) EN chinese hamster ovary cell, DNA replication, mean lethal dose, autoradiography [mammalia-unspecified and extinct, Cricetidae] 69023134

00663 Alterations in the Radio Sensitivity of Chinese Hamster Ovary Cells by Anisotonic Treatments Correlations between Cell Lethality and Chromosomal Aberrations Raaphorst, G.P., et al.: ibid., 79, (2) 403 16 (1979) EN X irradiation, chromatin, mean lethal dose, division delay mitosis, sodium chloride [Cricetidae] 69044063

00664 ESR of ${ }^{125}$ I Labeled Iododeoxy Uridine Labeled Cells and X Irradiated Cells at 4.2 $K$ and Above

Johnson, J.E., et al.: ibid., 80, (1) 24 37 (1979) EN L-1210 mouse leukemia, BP-8 mouse sarcoma, DNA, thymine [Muridae] 69054182

00665 Influence of Gamma Irradiation on the Development of Neoplastic Disease in Mice 1. Reticular Tissue Tumors

Ullrich, R.L., et al.: ibid., 80, (2) 303 16 (1979) EN reticulum cell, sarcoma, thymic lymphoma, myeloid leukemia, mathematical model, sex difference [Muridae] 69051959

00666 Influence of Gamma Irradiation on the Development of Neoplastic Disease in Mice 2. Solid Tumors

Ullrich, R.L., et al.: ibid., 80, (2) 317 24 (1979) EN mathematical model, ovarian tumor, pituitary harderian gland [Muridae] 69051960

00667 Influence of Gamma Irradiation on the Development of Neoplastic Disease in Mice 3. Dose Rate Effects

Ullrich, R.L., et al.: ibid., 80, (2) 325 42 (1979) EN mathematical model, carcinogenesis, reticular tissue, solid tumor [Muridae] 69051961

00668 Growth and Survival of Irradiated Cultured Mouse Thymic Nonlymphoid Cells Watkins, E.B., et al.: Res. J. Reticuloendothel. Soc., 26, (3) 209 20 (1979) EN macrophage, $\gamma$-irradiation [Muridae] 69021212

00669 The Effects of Typhoid, Paratyphoid A, Paratyphoid B, Endo Toxin and of Adrenergic Blocking Drugs on the Course of the Experimental Irradiation Disease

Voicu, V., et al.: Rev. Roum. Morphol. Embryol. Physiol. 15, (2) 127 32 (1978) EN rat propranolol dibenzyline autonomicdrug [Enterobacteriaceae, Muridae] 69012922

$\begin{array}{ll}00553 \text { (p. 52, 左) } & 00581 \text { (p. 54, 左) } \\ 00562 \text { (p. 52, 右) } & 00582 \text { (p. 54, 左) } \\ 00570 \text { (p. 53, 右) } & 00583 \text { (p. 54, 左) } \\ 00571 \text { (p. 53, 右) } & 00588 \text { (p. 54, 右) } \\ 00572 \text { (p. 53, 右) } & 00589 \text { (p. 55, 左) } \\ 00577 \text { (p. 54, 左) } & 00592 \text { (p. 55, 左) } \\ 00578 \text { (p. 54, 左) } & 00595 \text { (p. 55, 左) }\end{array}$

00579 (p. 54, 左)

$$
\text { [7]その他 }
$$

00670 Conformation of Cyclic AMP in Solution as Studied by the NMR Deuterium Substitution Effect on Relaxation Times Method 2. Self Association and Temperature Dependent Glycosidic Isomerization at $\mathbf{p H} 7$

Hayashi, F., et al.: Biochim. Biophys. Acta, 588, (2) 181 92 (1979) EN [Thermodynamics] 69062344

00671 Electrophilic Reactions of Chlorin Derivatives and a Comprehensive Collection of ${ }^{13} \mathrm{C}$ Data of these Products and Closely Related Compounds Wray, V., et al.: Tetrahedron, 35, (19) 2275 84 (1979) EN NMR 70007259 
医学・薬学文献題目集

\section{〔0]藏器に無関係のもの}

Distribution and fate in the rabbit of liposomes containing $\left({ }^{131} \mathbf{I}\right)$-sodium iodide. Hardy, J.G., et al.: Br. J. Pharmacol., 67, (3) 459 (1979) EN liposomes/matabolism; tissue distribution 01463 [0: D]

The application of robust calibration to radioimmunoassay. Tiede, J.J., et al.: Biometrics, 35, (3) 567 74 (1979) EN calibration; radioimmunoassay; statistics 01464 [0: E]

Failure to detect circulating immune complexes in allergic patients on injection therapy. Kemler, B.J., et al.: Clin. Allergy, 9, (5) 473 78 (1979) EN allergens, antigen-antibody complex; human; hypersensitivity; radioimmunoassay; time factors 01465 [0: E]

Radioimmunoassay measurement of prostaglandins E2 and F2 alpha in human urine. Ciabattoni, G., et al.: J. Endocrinol. Invest., 2, (2) $173 \sim 82$ (1979) EN cross reactions; radioimmunoassay $01466[0: \mathrm{E}]$

IgE determination (rist, prist and others). Ito, K.: 日本臨床, suppl., 1490 96 (1979) JA IgE methods; radioimmunoassay 01467 [0: E]

Ultrasensitive enzymatic radioimmunoassay: Application to detection of cholera toxin and rotavirus. Harris, C.C., et al.: Proc. Natl. Acad. Sci. USA., 76, (10) 5336 39 (1979) EN alkaline phosphatase; cholera toxin; comparative study; enzyme-linked immunosorbent assay; radioimmunoassay; RNA viruses; rota- virus 01468 [0: E]

Prostaglandins contribute to the vasodilation induced by nicotinic acid. Eklund, B., et al.: Prostaglandins, 17, (6) 821 30 (1979) EN chromatography; forearm/blood supply; human; naproxen/ nicotinic acids; prostaglandin antagonists; prostaglandins $\mathrm{E}$; radioimmunoassay; secretory rate; vasodilation 01469 [0: E]

Applications and limitations of measurement of 15-keto, 13,14-dihydro prostaglandin E2 in human blood by radioimmunoassay. Metz, S.A., et al.: ibid., 17, (6) 839 61 (1979) EN blood preservation; epinephrine/ fatty acids, nonesterified; hemolysis/ lipolysis; prostaglandins $\mathrm{E}$ radioimmunoassay; time factors; $01470[0: \mathrm{E}]$

New radiopharmaceuticals including ${ }^{123} I$. (Abstr., Proc. Br. Inst. Radiol.) Br. J. Radiol.; 52, (621) 762 65 (1979) EN 01471 [0: G]

Radioactive and radiation standards. (V). 4. Unsealed radioactivity standards for general use. Hamada, T.: Radioisotopes, 28, (7) 471 78 (1979) JA reference standards; solutions 01472 [0: Z]

01577 (p. 122, 右)

\section{[1]脳, 脳槽脊髄腔, 神経}

Quantitative in vivo autoradiography with positron emission tomography. Raichle, $M$. E.: Brain Res., 180, (1) 47 68 (1979) EN animal; autoradiography; blood volume; brain/ radionuclide imaging; carbon dioxide; carboxyhemoglobin; cerebrovascular circulation; human;

\section{分 類 項 目 表 (1979年11月 分類項目一部改訂)}

\section{表 1 臟器を中心とする分類}
0. 蔵器に無関係のもの
1. 脳, 脳槽脊髄脭, 神経
2. 甲状腺, 副甲状腺
3. 肺, 呼吸器
4. 心, 大血管
5. 肝, 胆道
6. 消化管, 喠液腺
7. 粹
8. 腎, 副腎
9. 生殖器 (前立腺, 胎児, 胎盤, 乳腺)
12. 末梢循環
13. リンパ, 水, 電解質
10. 骨, 関節, 筋
11. 血液, 骨髄, 脾

\section{表 2 方法, 目的を中心とする分類}
A. イメージング
B. 動態
C. 摄取率, 排泄率
D. 代謝，プール測定
E. イムノォ
ッセイ,インビトロ・テスト $\mathrm{F}$
F. 機器, データ処理
G. 薬郕, RI 製造 H
H. 被曝線量, 有害
作用 I . オートラジオグラフィ
J . 放射化分析
K. 治療
L. 薬理
Z. その他 
医学・薬学文献題目集

regional blood flow; tomography, emission computed 01473 [1: A]

The physical performances of a single slice positron tomographic system and preliminary results in a clinical environment. Soussaline, F., et al.: Eur. J. Nucl. Med., 4, (4) 237 49 (1979) EN brain/radionuclide imaging; carbon dioxide/cerebrovascular disorders/metabolism; elementary particles; evaluation studies; human; oxygen consumption; tomography, emission computed/ instrumentation 01474 [1: A, F]

Organic depression. Vardi, J., et al.: Isr. Ann. Psychiatry, 17, (2) 110 21 (1979) EN brain diseases; human; psychological tests; radioimmunoassay; serum albumin, radio-iodinated/ diagnostic use; tomography, X-ray computed 01475 [1: A, E]

RIHSA cisternography in cerebral tumours. Van Crevel, H.: Neuroradiology, 18, (3) 133 38 (1979) EN human; serum albumin, radio-iodinated/diagnostic use $01476[1,15: \mathrm{A}]$

Nuclear imaging agents: Ventricular visualization-brain imaging. Semin. Nucl. Med., 9, (2) 144 (1979) EN choroid plexus 01477 [1: A]

"Hyperfrontal" distribution of the cerebral grey matter flow in resting wakefulness; On the functional anatomy of the conscious state. Ingvar, D.H.: Acta Neurol. Scand., 60,

(1) 12 25 (1979) EN alcoholism; alpha rhythm; cerebral cortex; cerebrovascular circulation; consciousness; memory disorders; rest; temporal lobe 01478 [1: B]

Cerebral regional circulation dynamics. Uemura, K.: 日本臨床 suppl., 1882 83 (1979) JA cerebrovascular circulation; hemodynamics; xenon 01479 [1: B]

Serum myelin basic protein, clinical responsiveness, and outcome of severe head injury. Thomas, D.G., et al.: Acta Neurochir. (Wien)., 1, (suppl. 28) 93 95 (1979) EN acute; coma; encephalitogenic basic proteins; human; radioimmunoassay $01480[1: \mathrm{E}]$

Gastrin in human cerebrospinal fluid: Lack of correlation with serum concentrations. Kruse-Larsen, C., et al.: Brain Res., 176, (1) 189 91 (1979) EN comparative study; human; radioimmunoassay $01481[1,6: \mathrm{E}]$
Oligoclonal banding in the cerebrospinal fluid of patients with postencephalitic parkinsonism. Williams, A., et al.: J. Neurol. Neurosurg. Psychiatry, 42, (9) 790 92 (1979) EN antibodies, viral; human; radioimmunoassay 01482 [1: E ] 01556 (p. 121, 左)

\section{〔2〕甲状腺, 副甲状腺}

The 24-hour thyroidal uptake test. Werner, S.C., Semin. Nucl. Med., 9, (3) 156 58 (1979) EN 01483 [2: B]

Substance $P$ in medullary carcinoma of the thyroid. Skrabanek, P., et al.: Experientia, 35, (9) 1259 60 (1979) EN carcinoid tumor; radioimmunoassay; substance $P$; thyroid neoplasms 01484 [2: E]

Solid phase radioimmunoassay for thyroxine $\left(\mathbf{T}_{4}\right)$. Fukuchi, M., et al.: ホルモンと臨床, 27, (8) $915 \sim 19 \quad$ (1979) JA radioimmunoassay; reagent kits, 01485 [2: E]

Studies on solid phase RIA for TBG (CIS). Kajita, Y., et al.: ibid., 27, (8) 921 26 (1979) JA alpha globulins; pregnancy; radioimmunoassay; reagent kits 01486 [2: E]

Fundamental and clinical evaluation of gamma-DAB TSH radioimmunoassay kit. Ban. Y., et al.: ibid., 27, (8) 927 32 (1979) JA radioimmunoassay; reagent kits, thyrotropin 01487 [2: E]

Peripheral metabolism of reverse triiodothyronine $\left(T_{3}\right)$ in man. Zaninovich, A.A., et al.: Medicina, (B Aires) 39, (2) 235 38 (1979) SP thyroidectomy (Engl. Abstr. 付) 01488 [2: E]

Changes of plasma levels of TRH and its target hormones by two hour constant intravenous infusion of TRH tartrate in man. Nihei. N., et al.: 日本内分泌学会雑誌，55，(9) 1089 97 (1979) JA hormones, synthetic/administration \& dosage; human; infusions, parenteral; radioimmunoassay; thyrotropin; thyroxine/blood; triiodothyronine (Engl. Abstr. 付) 01489 [2: E,L]

The interrelation of serum levels of thyroxine, triiodothyronine and thyrotropin in acquired athyreotic subjects. Michaud, P., et al.: Rev. Med. Chil., 107, (4) 301 03 (1979) SP hypothyroidism; thyroidectomy (Engl. Abstr. 付) $01490[2: \mathrm{E}]$ 
医学・薬学文献題目集

The effect of thyrotropin on extra-thyroid conversion of thyroxin to triiodothyronine in patients with acquired athyreosis. Michaud, P., et al.: ibid., 107, (4) 304 07 (1979) SP hypothyroidism; thyroidectomy (Engl. Abstr. 付) $01491[2: \mathrm{E}]$

Skin fibrosis in hyperthyroidism treated by sotalol and radioactive iodine. Bonnetblanc, J.M., et al.: Ann. Dermatol. Venereol., 106, (6/7) 583 88 (1979) FR (Engl. Abstr. 付) 01492 [2: L, H] 01504 (p. 117, 右)

\section{[3]肺, 呼吸器}

Ventilation-perfusion studies in suspected pulmonary embolism. Biello, D.R., et al.: A.J.R., 133, (6) 1033 37 (1979) EN artery/radiography; xenon radioisotopes 01493 [3: A]

The history of lung imaging with radionuclides. Taplin, G.V.: Semin. Nucl. Med., 9, (3) $178 \sim 85$ (1979) $\mathrm{EN} 01494$ [3: A]

Imaging sites of airway obstruction and measuring functional responses to bronchodilator treatment in asthma. Chopra, S.K., et al.: Thorax, 34, (4) 493 500 (1979) EN terbutaline; xenon radioisotopes 01495 [3: A, B]

\section{[4]心，大血管}

Value and limitations of ${ }^{99 m} \mathbf{T c}$ stannous pyrophosphate in the detection of acute myocardial infarction. Codini, M.A., et al.: $A m$. Heart J., 98, (6) 752 62 (1979) EN infarction/ radionuclide imaging; 01496 [4: A]

The comparison between non-invasive and invasive methods of stroke volume determination in children. Alpert, B.S., et al.: ibid., 98, (6) 763 66 (1979) EN angiography; cardiac output; comparative study; dyes; echocardiography; radionuclide imaging; stroke volume 01497 [4: A]

Evaluation of radioactive phosphate scintillography in relation to time elapsed after acute myocardial infarct. Cuar'on, A., et al.: Arch. Inst. Cardiol. Mex., 49, (4) 604 16 (1979) SP phosphorus radioisotopes; time factors (Engl. Abstr. 付) 01498 [4: A]

Redistribution of thallium at rest in patients with stable and unstable angina and the effect of coronary artery bypass surgery. Berger, B.C., et al.: Circulation, 60, (5) 1114 25 (1979) EN angina pectoris/radionuclide imaging; aortocoronary bypass; electrocardiography; heart catheterization; radionuclide imaging; human; myocardium; postoperative period 01499 [4: A]

Reliability of stress ${ }^{201} \mathrm{Tl}$ scanning in the clinical evaluation of coronary artery disease. Stolzenberg, J., et al.: Clin. Nucl. Med., 4, (6) 225 $\sim 28$ (1979) EN electrocardiography; evaluation studies; exercise test; heart catheterization; human; middle age 01500 [4: A]

Value of the radiocardiographic studies for qualification of patients with mitral valve defects for surgical treatment. Szymczy'nska, A., et al.: Kardiol. Pol., 22, (4) 435 44 (1979) PL hemodynamics; human; indium/ mitral valve stenosis/ radioisotope dilution technic (Engl. Abstr. 付) 01501 [4: B]

Measurement of regional myocardial perfusion ${ }^{133} \mathrm{Xe}$ method and others. Yonekura, Y.: 日本臨床, suppl., 2011 12 (1979) JA coronary circulation; radionuclide imaging; regional blood flow; thallium; xenon 01502 [4: B, A]

Some observations on serum concentrations of digitoxin and digoxin. Takahashi, M., et al.: JPN. Heart J., 20, (5) 623 29 (1979) EN heart diseases/drug therapy; human; radioimmunoassay $01503[4: \mathrm{E}]$

Serum levels of 3,5, 3'-triiodothyronine, 3,3', 5 '-triiodothyronine and thyroxine in acute myocardial infarction. Longhini, C., et al.: Ric. Clin. Lab., 9, (2) 197 205 (1979) EN triiodothyronine, reverse $01504[4,2: \mathrm{E}]$

Use of radioallergo-and radioimmunosorbent methods in the diagnosis of allergic reactions to bicillin and penicillin in children with rheumatism. Khabizhanov, B.K.H.: Vopr. Reum., (3) 37 41 (1979) RU case report; drug hypersensitivity (Engl. Abstr. 付) 01505 [4: E]

\section{〔5]肝, 胆道}

Measurement of colloid clearance rate as an adjunct to static liver imaging. Miller, J., et al.: Eur. J. Nucl. Med., 4, (1) 1 5 (1979) EN computers; diagnosis, differential; human; 


\section{医学・薬学文献題目集}

liver diseases/ radionuclide imaging; sulfur; technetium 01506 [5: A, B]

Uptake of ${ }^{67} \mathrm{Ga}-6-\mathrm{mercaptopurines}$ in morris hepatoma-3924 A. Guarino, A., et al.: ibid., 4, (3) $211 \sim 15$ (1979) EN hepatoma, experimental/ metabolism; liver neoplasms/radionuclide imaging; rats 01507 [5: A, D]

Simple, fast preparation of ${ }^{68} \mathrm{Ga}$-labelled human serum albumin microspheres. Yvert, J.P., et al.: ibid., 4, (2) 95 99 (1979) EN comparative study; hydrogen-ion concentration; isotope labeling/methods; rats; strontium radioisotopes/metabolism; tissue distribution 01508 [5: D, G]

Evaluation of one dimensional profile scans with a whole body counter- ${ }^{82} \mathrm{Br}$ space in liver cirrhosis: Concise communication. Schober, O., et al.: ibid., 4, (3) 231 34 (1979) EN extracellular space/radionuclide imaging 01509 [5: D]

Autoimmune implications of immune complexes in clinical variants of hepatitis $B$. Daugharty, H., et al.: Clin. Exp. Immunol., 37, (2) $213 \sim 20$ (1979) EN antigen-antibody complex; IgG, IgM; platelet aggregation 01510 [5: E]

\section{〔6] 消化管, 唾液腺}

A single scan technique for estimating acid output. Taylor, T.V., et al.: Gastroenterology, 77, (6) 1241 44 (1979) EN gastric acidity determination; human; pentagastrin; radionuclide imaging technetium 01511 [6: $\mathrm{A}, \mathrm{G}]$

Serum cholecystokinin, basal acid secretion, and infantile pyloric stenosis. Rogers, I.M., et al.: Arch. Dis. Child., 54, (10) 773 75 (1979) $\mathrm{EN}$ gastric juice 01512 [6: E]

Production of a specific antiserum by synthetic C-terminal fragment of glucagon.

Ohneda, A., et al.: Horm. Metab. Res., 11, (8) $463 \sim 68$ (1979) EN amino acid sequence; cross reactions; human; immune sera; peptide fragments; radioimmunoassay 01513 [6, 14: E]

Failure of diagnosis of pernicious anaemia by radioassay of ${ }^{12}$ B. Scott, J.M., et al.: Ir. Med. J., 72, (10) 419 23 (1979) EN diagnosis, differential; human; radioimmunoassay 01514 [6: E]
Radioimmunoassay of human intestinal goblet cell mucin. Investigation of mucus from different organs and species. Qureshi, R., et al.: J. Clin. Invest., 64, (5) $1149 \sim 56$ (1979) EN autoantigens 01515 [6: E]

01481 (p. 116, 左)

\section{〔7〕脺}

Immune complexes in diabetes mellitus. Charlesworth, J.A., et al.: Aust. NZ. J. Med. 9, (4) 370 73 (1979) EN Burkitt's lymphoma; cell line 01516 [7: E]

Measurement of human proinsulin by an indirect two-site immunoradiometric assay. Rainbow, S.J., et al.: Diabetologia., 17, (4) 229 34 (1979) EN antigenic determinants; diabetes mellitus; human; islet cell tumor; rabbits; radioimmunoassay/methods; sheep 01517 [7 : E, L]

Indirect two-site immunoradiometric assay of rat and mouse proinsulin. Yue, D.K., et al.: ibid., 17, (4) 235 42 (1979) EN comparative study; glucose/pharmacodynamics; human; insulin; radioimmunoassay/methods; rats 01518 [7: E, L]

Concentration of porcine proinsulin-like material in plasma of insulin-treated diabetics in relation to purity of insulin preparations. Aaby, P.: Horm. Metab. Res., 11, (8) 455 57 (1979) EN diabetes mellitus, juvenile; human; insulin antibodies; radioimmunoassay 01519 [7, 14: E]

Immune complexes in newly diagnosed insulin-dependent (type I) diabetics. Irvine, W.J., et al.: J. Clin. Lab. Immunol., 1, (3) 183 86 (1978) EN complement 1; diabetes mellitus/drug therapy; human; islands of langerhans; radioimmunoassay 01520 [7, 14: E, K] 01571 (p. 122, 左)

\section{〔8〕腎, 副腎}

Cholesteryl iodide- ${ }^{125} \mathrm{I}$ as a diagnostic adrenal photoscanning agent. Part-1. Aboul-Enein, H.Y., et al.: Res. Commun. Chem. Pathol. Pharmacol., 25, (3) 611 14 (1979) EN 01521 [8, 14: A]

Plastic surgery in hydronephrosis (indications and follow-up. Isotope nephrographic studies). Kracht, H., et al.: Int. Urol. Nephrol., 11, (3) $173 \sim 83$ (1979) $\mathrm{EN}$ follow-up studies; 


\section{医学・薬学文献題目集}

human; radioisotope renography; ureter 01522 [8: B]

Release of prostaglandins into the pelvic venous blood of dogs in response to vesical distension and pelvic nerve stimulation. Khalaf, I.M., et al.: Invest. Urol., 17, (3) 244 47 (1979) EN analysis of variance; dogs; radioimmunoassay 01523 [8: E]

A sensitive radioimmunoassay for the determination of plasma angiotensin II in human subjects. Kobayashi, H., et al.: Jpn. Circ. J., 43, (8) 727 33 (1979) EN angiotensin II/isolation \& purification; dose-response relationship, drug; furosemide; human; radioimmunoassay/methods; renin $01524[8,14: \mathrm{E}, \mathrm{L}]$

Importance of the radioimmune method of determining renin activity in the blood plasma for the differential therapy of hypertension. Koroliuk, I.P., et al.: Kardiologiia., 19, (10) 49 51 (1979) RU circadian rhythm; comparative study; human; hypertension/drug therapy; radioimmunoassay (Engl. Abstr. 付) 01525 [8: E]

\section{[9]生殖器 (前立腺, 胎児, 胎盤, 乳腺)}

Image recognition and the reconstruction of cleft palate histological preparations: A new approach. Siegel, M.I., et al.: Cleft. Palate. J., 16, (4) 381 84 (1979) EN cleft palate/ radionuclide imaging; fetus; human; pregnancy; tomography, emission computed $01526[9: \mathrm{A}]$

Tumor markers in testicular cancer. Catalona, W.J.: Urol. Clin. North Am., 6, (3) 613 28 (1979) EN alpha fetoproteins; gonadotropins, review $01527[9,15: \mathrm{D}, \mathrm{E}]$

Hormone production during pregnancy in the primigravid patient. 1. Plasma levels of progesterone and 5-alpha-pregnane-3, 20-dione throughout pregnancy of normal women and women who developed pregnancyinduced hypertension. Parker, C.R.Jr., et al.: Am. J. Obstet. Gynecol., 135, (6) 778 82 (1979) EN comparative study; female; hypertension; pregnancy complications, cardiovascular; pregnancy trimester, first; pregnancy trimester, third; pregnanediones; progesterone radioimmunoassay 01528 [9: E]

Serum prolactin in male infertility. Rjosk,
H.K., et al.: Andrologia, 11, (4) 297 304 (1979) EN cell count; FSH; human; LH; prolactin; radioimmunoassay; sperm motility; spermatozoa; sterility, male; testosterone 01529 [9: E]

Investigation and management of symptomatic hyperprolactinaemia. Holdaway, I.M., et al.: Aust. NZ. J. Obstet. Gynaecol., 19, (2) 100 $\sim 06$ (1979) EN adenoma; amenorrhea/estrogens galactorrhea; LH; pituitary neoplasms 2-bromoergocryptine 01530 [9: E]

The level of urinary and plasma steroids after oral administration of cyclofenil to hirsute women with menstrual disorders and obesity. Cioc'irdia, C., et al.: Endocrinologie, 17, (3) 197 200 (1979) EN cresols; estradiol; progesterone; testosterone 01531 [9: E]

Association between duffy blood groups and serum level of the pregnancy zone protein. Beckman, L., et al.: Hum. Hered., 29, (5) 257 60 (1979) EN abo blood-group system; duffy blood-group system; human; pregnancy proteins; pregnancy zone proteins; psoriasis; radioimmunoassay 01532 [9: E]

Serum progesterone and estradiol in pregnant women selected for progestagen treatment. Dubin, N.H., et al.: Int. J. Fertil., 24, (2) 86 93 (1979) EN 01533 [9: E]

Detection of beta subunit HCG in plasma of IUD users as an indication of frequency of conception. Nilsson, C.G., et al.: ibid., 24, (2) 134 37 (1979) EN human; intrauterine devices, copper; LH; pregnancy tests; progesterone; radioimmunoassay $01534[9,14: \mathrm{E}]$

The significance of positive chorionic gonadotropins in apparently pure seminoma of the testis. Mauch, P., et al.: Int. J. Radiat. Oncol. Biol. Phys., 5, (6) 887 89 (1979) EN castration; dysgerminoma; human; radioimmunoassay; radiotherapy, high energy; 01535 [9: E, K]

Unconjugated and total estriol in human amniotic fluid-changes in the ratios between the two estriol levels with advancing gestational age. Bacigalupo, G., et al.: J. Perinat. Med., 7, (5) 262 69 (1979) EN 01536 [9: E]

Determination of serum progesterone levels using a direct ${ }^{125}$ I-radioimmunoassay. Rousell, R.H., et al.: Ric. Clin. Lab., 9, (2) 185 95 
医学・菜学文献題目集

(1979) EN sterility 01537 [9: E]

Improved accuracy in the clinical diagnosis of ectopic pregnancy by the simultaneous use of pelvic ultrasonography and a radioreceptor assay of human chorionic gonadotropin. Pelosi, M.A., et al.: Surg. Gynecol. Obstet., 149, (4) 539 44 (1979) EN case report; gonadotropins, chorionic/urine 01538 [9: E]

Acid phosphatase. Henneberry, M.O., et al.: Urol. Clin. North Am., 6, (3) 629 41 (1979) EN bone marrow/enzymology; counterimmunoelectrophoresis; prostatic neoplasms 01539 [9: E]

Laboratory tools in the diagnosis of prostatic cancer. Jacobi, G.H.: Urologe $(A), 18$, (6) $311 \sim 15$ (1979) DE acid phosphatase/analysis; alkaline phosphatase/analysis; androstanes; carcinoembryonic antigen (Engl. Abstr. 付)

01540 [9: E]

01559 (p. 121, 左) 01584 (p. 123, 左)

\section{〔10] 骨，関節，筋}

The urinary excretion of ${ }^{67} \mathrm{Ga}$ citrate in patients with neoplastic disease. Zivanovic, M. A., et al.: Eur. J. Nucl. Med., 4, (4) $277 \sim 82$ (1979) EN bone neoplasms/radionuclide imaging; comparative study; human; neoplasms/drug therapy; neoplasms/ radiotherapy; prognosis $01541[10,15: \mathrm{A}, \mathrm{K}]$

Clinical evaluation of ${ }^{67} \mathrm{Ga}$-citrate in nonhodgkin's lymphoma. Oshiumi, Y., et al.: 臨 床放射線, 24, (10) 1181 89 (1979) JA bone and bones/radionuclide imaging; Hodgkin's disease/ classification; human; neoplasm staging; technetium (Engl. Abstr. 付) 01542 [10: A]

An historical survey of bone scanning. Ram, P.C., et al.: Semin. Nucl. Med., 9, (3) 190 96 (1979) EN 01543 [10: A]

Radioactive ${ }^{90} \mathbf{Y}$ intra-articularly for the treatment of rheumatoid arthritis-1-year follow up. McCoy, J.M.: J. Med. Assoc. Ga., 68, (11) 980 81 (1979) EN human; yttrium radioisotopes/administration \& dosage; 01544 [10: K]

Beta-2-microglobulin and rheumatic diseases. Manicourt, D.: Acta Rhumatol., 3, (1) 13 $\sim 28$ (1979) FR arthritis, rheumatoid; autoimmune diseases; beta globulins/analysis; bone resorption; complement 3, complement 4; human; leukocyte count; radioimmunoassay; synovial fluid (Engl.
Abstr. 付) $01545[10,11: \mathrm{L}, \mathrm{Z}]$

\section{〔11〕血液, 骨髄, 脾}

${ }^{131}$ I labelled ioglycamic acid (biligram) for scintiscanning in hepatobiliary disorders. Blackwell, J.N., et al.: Eur. J. Nucl. Med., 4, (1) $7 \sim 11$ (1979) EN biliary tract diseases/radionuclide imaging; half-life; iodobenzoates; ioglycamic acid; kinetics; liver diseases 01546 [11: A]

Quantitative organ-uptake measurement with a gamma camera. Ferrant, A., et al.: ibid., 4, (3) 223 29 (1979) EN erythrocytes/radionuclide imaging; human; models, biological; models, structural; splenomegaly/radionuclide imaging; sulfur/diagnostic use; technetium/diagnostic use $01547[11,15: \mathrm{A}, \mathrm{D}]$

Application of ferrokinetic investigation for differential diagnosis in bone marrow hypoplasia and their clinical relevance. Gupta, M., et al.: ibid., 4, (1) 17 20 (1979) EN 01548 [11: B]

Studies of density fractions of normal human erythrocytes labeled with ${ }^{59} \mathrm{Fe}$ in vivo. Luthra, M.G., et al.: J. Lab. Clin. Med., 94, (6) 879 96 (1979) EN adenosine triphosphate; cell separation; erythrocyte aging; hemoglobins; human; osmotic fragility 01549 [11: D]

Platelets and ${ }^{125}$ I-labelled staphylococcal protein $A$ in the detection of immune complexes in serum. Kekomeaki, R., et al.: $J$. Clin. Lab. Immunol., 1, (4) 305 09 (1979) EN arthritis, rheumatoid; crohn disease DNA; glomerulonephritis; human; lipopolysaccharides; lupus erythematosus, systemic neoplasms; onchocerciasis; platelet aggregation; thrombopenia; vasculitis 01550 [11: E, L]

AG in platelets from patients with various forms of von Willebrand's disease. Holmbeg, L., et al.: Thromb. Haemost., 42, (3) 1033 38 (1979) EN endothelium; factor viii 01551 [11: E]

A plasma-error-free method of hematocrit determination using radionuclides. Hopfer, F., et al.: Z. Med. Lab. Diagn., 20, (4) 208 11 (1979) DE radio-iodinated (Engl. Abstr. 付) 01552 [11: E]

A coagulo-radioimmunometric assay for the quantitation of fibrin monomer in human 


\section{医学・薬学文献題目集}

plasma. Principles and development of the method. F'elez, J., et al.: Thromb. Res., 16, (1/2) 175 89 (1979) EN fibrinogen; iodine radioisotopes 01553 [11: E]

Purification of a heparin-neutralizing protein from rabbit platelets and its homology with human platelet factor 4. Ginsberg, M.H., et al.: J. Biol. Chem., 254, (24) 12365 71 (1979) EN 01554 [11: G, E]

Sequence of fibrinogen proteolysis and platelet release after intrauterine infusion of hypertonic saline. Nossel, H.L., et al.: $J$. Clin. Invest., 64, (5) $1371 \sim 78$ (1979) EN 01555 [11: G]

01545 (p. 120, 左)

\section{〔14〕内 分 泌}

Serum levels of somatomedin $A$ and growth during long-term treatment of patients with pituitary dwarfism with human growth hormone. Takano, K., et al.: Acta Endocrinol. (Copenh.), 92, (3) 385 97 (1979) EN age determination by skeleton; body height/drug effects; pituitary/drug therapy; administration \& dosage; somatotropin/blood 01556 [14, 1: E]

Determination of serum levels of thyroxine, triiodothyronine, testosterone and dehydroepiandro sterone of xikrin and surui indians. Vieira, Filho, J.P., et al.: $A M B, 25$, (6) 208 10 (1979) PT human; South American; radioimmunoassay (Engl. Abstr. 付) 01557 [14: E]

Laboratory assessment of prolactin status. Cowden, E.A., et al.: Ann. Clin. Biochem., 16, (3) 113 21 (1979) EN circadian rhythm; human; hypophysectomy; hypothalamo-hypophyseal system; hypothyroidism; kidney failure, chronic ; levodora; metoclopramide; radioimmunoassay 01558 [14: E]

Somatomedin-like activity, prolactin, growth hormone and insulin in human cord blood. Brinsmead, M.W., et al.: Aust. NZ. J. Obstet. Gynaecol., 19, (3) 129 34 (1979) EN fetal blood/ metabolism; human; insulin/blood; pregnancy complications; somatotropin/blood 01559 [14, 9: E]

Serum cortisol and 11 deoxycortisol by liquid chromatography: Clinical studies and comparison with radioimmunoassay. Canalis, E., et al.: Clin. Chem., 25, (10) 1700 03 (1979) EN chromatography; corticotropin; dexamethasone; insulin; radioimmunoassay 01560 [14: E]

Improved radioimmunoassay for 11-deoxycortisol (compound S) in plasma. Demers, L.M., et al.: ibid., 25, (10) 1704 07 (1979) EN chromatography; cortodoxone; radioimmunoassay 17 hydroxycorticosteroids 01561 [14: E]

Radioimmunoassay of circulating melatonin in man. Yoshida, K., et al.: ホルモンと臨床, 27, (8) 873 77 (1979) JA circadian rhythm; melatonin 01562 [14: E]

Characterization of lipotropin-, corticotropin-, and beta-endorphin-immunoreactive materials secreted in vitro by a human pituitary adenoma responsible for a case of Nelson's syndrome. Bertagna, X., et al.: $J$. Clin. Endocrinol. Metab., 49, (4) 527 32 (1979) EN adenoma/secretion; human; pituitary neoplasms/complications; pituitary neoplsms/physiopathology 01563 [14: E]

Direct radioiodination of estradiol for a sensitive radioimmunoassay. Malmquist, M., et al.: ibid., 49, (4) 655 57 (1979) EN 01564 [14: G]

Widespread distribution of a chorionic gonadotropin-like substance in normal human tissues. Braunstein, G.D., et al.: ibid., 49, (6) 917 25 (1979) EN chromatography, affinity; chromatography, gel; concanavalin A; ovary; radioligand assay; testis; tissue distribution 01565 [14: E]

Modulation of homologous receptor concentrations: A sensitive radioassay for human growth hormone in acromegalic, newborn, and stimulated plasma. Rosenfeld, R.G., et al.: ibid., 50, (1) 62 69 (1980) EN arginine/ diagnostic use; human; insulin/diagnostic use; levodopa/diagnostic use; radioimmunoassay; hormone/metabolism; somatotropin/blood 01566 [14: E]

Evidence from radioligand assays that somatomedin-C and insulin-like growth factorI ARE similar to each other and different from other somatomedins. Van Wyk, J.J., et al.: ibid., 50, (1) 206 08 (1980) EN comparative study; human; nonsuppressible insulin-like activity; radioimmunoassay 01567 [14: E] 
医学・薬学文献題目集

Immunohistochemical characterization of monolayer cell cultures of embryonic chicken pancreas and measurement of somatostatin release. Barden, N., et al.: J. Histochem. Cytochem., 27, (5) 939 41 (1979) EN 01568 [14: E]

Prostacyclin overproduction in Bartter's syndrome. Geullner, H.G., et al.: Lancet, 2, (8146) 767 69 (1979) EN arachidonic acids; blood pressure; hyperaldosteronism; prostaglandins; radioimmunoassay; thromboxane B2 vasoconstrictor agents 01569 [14: E]

Beta-endorphin immunoreactivity in rat and human blood: Radioimmunoassay, comparative levels and physiological alterations. Akil, H., et al.: Life Sci., 24, (18) 1659 65 (1979) EN adrenalectomy; corticotropin; human; hypophysectomy; lipotropin; rats 01570 [14: E]

Inhibition of glucose-induced insulin secretion by intravenous colchicine in man. Ertel, N.H., et al.: Metabolism, 28, (12) 1255 60 (1979) $\mathrm{EN}$ blood glucose/metabolism; calcium/blood; glucose tolerance test; human 01571 [14, 7: E]

Hormone receptors. Baxter, J.D., et al.: $N$. Engl. J. Med., 301, (21) 1149 61 (1979) EN adenosine cyclic monophosphate; adenyl cyclase; catecholamines; chromatin; DNA; enzyme activation; lipoproteins; radioligand assay; receptors, hormone; RNA; messenger; thyroid hormones; review 01572 [14: E]

New criteria for evaluation of acromegaly. Daughaday, W.H.: ibid., 301, (21) 1175 76 (1979) EN radioimmunoassay; somatomedin 01573 [14: E]

Prolactin response to thyrotropin-releasing hormone in normal and complicated late pregnancies. Kivinen, S., et al.: Obstet. Gynecol., 54, (6) 695 98 (1979) EN human; hypertension/blood; pre-eclampsia/blood; pregnancy complications/blood; radioimmunoassay 01574 [14: E]

Radioimmunoassay of arginine vasopressin in the plasma and urine. Sr'amkov'a, J., et al.: Physiol. Bohemoslov., 28, (5) 399 409 (1979) EN drinking; human 01575 [14: E]

01513 (p. 118, 左)

01524 (p. 119, 左)

01519 (p. 118, 右)

01534 (p. 119, 右)

01520 (p. 118, 右)

01604 (p. 124, 左)

01521 (p. 118, 右)

\section{〔15〕腫瘍，膿瘍}

${ }^{111}$ In labeled leukocytes in the evaluation of suspected abdominal abscesses. Coleman, R.E., et al.: Am. J. Surg., 139, (1) 99 104 (1980) EN abdomen/radionuclide imaging; case report; indium/diagnostic use; surgical wound infection/ radionuclide imaging 01576 [15: A]

Care of a patient who is to undergo A gallium scan. Chiarella, M.: Aust. Nurses J., 9, (2) 43 52 (1979) EN human; radionuclide imaging/nursing $01577[15,0: \mathrm{A}]$

${ }^{67}$ Ga scanning in pyrexia of unknown origin. Hilson, A.J., et al.: Br. Med. J., 2, (6201) 1330 $\sim 31$ (1979) EN fever of unknown origin 01578 [15: A]

Gallium scan in recurrent Hodgkin's disease in children. Yeh, S.D., et al.: Clin. Nucl. Med., 4, (9) 359 67 (1979) EN child; gallium radioisotopes/diagnostic use; Hodgkin's disease/ radionuclide imaging; Hodgkin's disease/radiotherapy; human; lymph nodes/radionuclide imaging; neoplasm recurrence, neoplasm staging 01579 [15: A]

${ }^{67} \mathrm{Ga}$ citrate in detecting recurrent rectal carcinoma after abdomino-perineal resection. Lentle, B.C., et al.: J. Can. Assoc. Radiol., 30, (3) 165 66 (1979) EN abdomen; diagnostic errors; human; neoplasm recurrence, local/radionuclide imaging; pelvic neoplasm; perineum, rectal neoplasms; retrospective studies 01580 [15: A]

Differentiation of retroperitoneal tumor using positron emission computed tomography. Buonocore, E., et al.: J. Comput. Assist. Tomogr., 3, (6) 825 28 (1979) EN carbon radioisotopes; diagnosis, differential; human; lymphosarcoma; pancreatic neoplasms; retroperitoneal neoplasm 01581 [15: A]

Retro-peritoneal tumors. Report of 21 cases. Clot, P., et al.: Sem. Hop. Paris, 55, (21/22) 1057 $\sim 64$ (1979) FR angiography; radionuclide imaging; tomography, X-ray computed (Engl. Abstr. 付) 01582 [15: A]

Human malignant melanoma antigenic properties of phenol water extracts. Suter, L., et al.: Arch. Dermatol. Res., 264, (1) 37 47 
医学・薬学文献題目集

(1979) EN antigens, neoplasm/isolation; human; melanoma/immunology; neoplasm metastasis; rabbits; radioimmunoassay 01583 [15: E]

The synthesis of the glycoprotein hormone alpha subunit by human breast carcinomas. Cove, D.H., et al.: Eur. J. Cancer, 15, (5) 693 702 (1979) EN cytosol; gonadotropins, chorionic; hormones, ectopic; immunoenzyme technics $01584[15,9: \mathrm{E}]$

Serial determination of marker substances in ovarian cancer. Stanhope, C.R., et al.: Gynecol. Oncol., 8, (3) 284 87 (1979) EN alpha fetoproteins; carcinoembryonic antigen; gonadotropins, chorionic placental lactogen; radioimmunoassay 01585 [15: E]

Prostaglandin E2 and cyclic AMP levels in human breast tumors. Feller, N., et al.: $J$. Cancer Res. Clin. Oncol., 93, (3) 275 80 (1979) EN adenosine cyclic-3', 5'-monophosphate/analysis; bone neoplasms; breast diseases; carcinoma human; neoplasm metastasis; radioimmunoassay 01586 [15: E]

Radioimmunoassay of carcinoembryonic antigen (CEA) without extraction and dialy sis using solid-phase antibody. Kollmann, G., et al.: J. Immunol. Methods, 29, (4) 387 94 (1979) EN 01587 [15: E]

Detection of tumor antibodies in patients with gastrointestinal carcinomas by a solidphase radioimmunoassay. Berczi, I., et al.: Jnci., 63, (3) 553 66 (1979) EN carcinoembryonic antigen; cross reactions 01588 [15: E]

Carcinoembryonic antigen content in tumors of the organs of the abdominal cavity and retroperitoneal space. Tkacheva, G.A., et al.: Med. Radiol. (Mosk.), 24, (8) 22 25 (1979) RU (Engl. Abstr. 付) 01589 [15: E]

Carcinoembryonic antigen. Yamaguchi, N., et al.: 日本消化器病学会雑誌, 76, (6) 1246 52 (1979) JA fluorescent antibody-technic; pancreatic neoplasms; radioimmunoassay; rectal neoplasms; stomach neoplasms 01590 [15: E]

Evaluation of a serial control of plasma levels of carcinoembrionic antigen (CEA) in cancer patients. Richart, C., et al.: Rev. Clin. Esp., 153, (4) 299 302 (1979) SP (Engl. Abstr. 付) $01591[15: \mathrm{E}]$
Drofacial tumours induced in rats with radioactive cerium chloride. Jasmin, J.R., et al.: Biomedicine, 30, (5) 265 70 (1979) $\{\mathrm{EN}$ 01592 [15: H]

Localization in interstitial dosimetry utilizing the CT scanner. Herskovic, A., et al.: Comput. Tomogr., 3, (2) 101 03 (1979) EN neoplasms; radiotherapy; radiographic magnification; radioisotopes; radiotherapy dosage 01593 [15: $\mathrm{K}, \mathrm{H}]$

Use of radioactive gold in the treatment of pleural effusions caused by metastatic cancer. Meohlen, K.H., et al.: J. Cancer Res. Clin. Oncol., 94, (1) 81 85 (1979) EN drainage; genital neoplasms, female/complications; adverse effects; human; neoplasm metastasis; pneumonia; pneumothorax; remission 01594 [15: $\mathrm{K}, \mathrm{H}]$ 01476 (p.116, 左) 01541 (p. 120,左) 01527 (p. 119, 左) 01547 (p. 120, 右)

\section{[30] そ の 他}

Scanning: Which technique? Husband, J.E., et al.: Br. J. Hosp. Med., 21, (6) 618 26 (1979) EN adrenal gland neoplasms; bone diseases; brain diseases; heart ' diseases; kidney diseases; liver diseases; pancreatic diseases; pelvic neoplasms; peritoneal neoplasms; thyroid diseases; tomography, emission computed; tomography, X-ray computed 01595 [30: A]

Nuclear medicine lin "paediatrics. (Abstr., Proc. Br. Inst. Radiol.) Br." J. Radiol., 52, (620) 676 79 (1979) EN congresses; Great Britain; human; lung/radionuclide; urinary tract/radionuclide imaging 01596 [30: A]

New methods of imaging in nuclear medicine. (Abstr., Proc. Br. Inst. Radiol.) ibid., 52, (620) 681 82 (1979) EN Great Britain; radionuclide imaging 01597 [30: A]

Merit of Ge and $\mathrm{NaI}(\mathrm{Tl})$ detectors as determined by imaging efficiency and scatter rejection. Strauss, M.G., et al.: Phys. Med. Biol., 24, (4) 702 10 (1979) EN comparative study; scattering, radiation 01598 [30: A, F]

Traumatic episcleritis following ${ }^{32} \mathbf{P}$ testing. Goldfarb, D. A., et al.: Arch. Ophthalmol., 98, (2) 331 34 (1980) EN choroid neoplasms/radionuclide imaging; foreign body reaction; melanoma 01599 [30: $\mathrm{B}, \mathrm{H}]$ 
医学・薬学文献題目集

Circulating immune complexes in lupus erythematosus, scleroderma and dermatomyositis. Solling, J., et al.: Acta Derm. Venereol. (Stockh.), 59, (5) 421 26 (1979) EN antigenantibody complex; complement 1,3,4; deoxyribonuclease; polyethylene glycols; precipitation; radioimmunoassay; receptors 01600 [30: E]

A direct radioimmunoassay for human urinary kallikrein. Oza, N.B., et al.: Adv. Exp. Med. Biol., 120A, 97 103 (1979) EN kallikrein/urine; kinetics; radioimmunoassay 01601 [30: E]

Enzyme immunoassay of bradykinin. Ueno, A., et al.: ibid., 120A, 195 202 (1979) EN bradykinin; comparative study; immunoenzyme technics; radioimmunoassay 01602 [30: E]

Human urinary kallikrein-biochemical and physiological aspects. Geiger, R., et al.: ibid., 120A, 235 44 (1979) EN comparative study; kallikrein/isolation \& purification; urine; pancreas; radioimmunoassay; species specificity 01603 [30: E]

Quality control of radioimmunoassays for proteins: The first two and a half years of a national scheme for serum growth hormone measurements. Hunter, W.M., et al.: Ann. Clin. Biochem., 16, (3) 131 46 (1979) EN Great Britain; human; laboratories; microchemistry $01604[30,14: \mathrm{E}, \mathrm{Z}]$

Radioimmunoassay of dehydroepiandrosterone and 5 -androstene-3- $\beta, 17-\beta$-diol in the plasma of psoriatics and controls. Morsches, B., et al.: Arch. Dermatol. Res., 266, (2) 181 85 (1979) DE psoriasis (Engl. Abstr. 付) 01605 [30: E]

Collagenase in human cornea: Immunologic localization. Gordon, J.M., et al.: Arch. Ophthalmol., 98, 341 45 (1980) EN clostridiopeptidase A; corneal ulcer; fluorescent antibody technic; radioimmunoassay 01606 [30: E]

Failure to detect type-C virus P30-related antigen in systemic lupus erythematosus: False-positive reaction due to protease activity. Kimura, M., et al.: Arthritis, Rheum., 23, (1) 111 13 (1980) EN protease inhibitors; radioimmunoassay 01607 [30: E]

Emergency estimations of paracuat in plasma. A comparison of the RIA and low pair/colorimetric methods. Stewart, M.J., et al.: Clin. Chim. Acta, 94, (3) 253 57 (1979) EN 01608 [30: E]

The significance of antibodies to poly (adenosine diphosphate-ribose)in systemic lupus erythematosus. Okolie, E.E., et al.: Clin. Exp. Immunol., 36, (1) 151 64 (1979) EN antibody specificity; antigen-antibody complex; arthritis, rheumatoid; autoantibodies; DNA; hepatitis nucleoside diphosphate sogars 01609 [30: E]

Stereoselectivity of a radioimmunoassay for the insecticide S-bioallethrin. Wing, K.D., et al.: Experientia, 35, (12) 1619 20 (1975) EN 01610 [30: E]

Radioimmunoassay of urinary cyclic AMP by Yamasa cyclic AMP assaiy kit. Schn, H., et al.: ホルモンと臨床, 27, (6) 671 76 (1979) JA adenosine cyclic-3', 5'-monophosphate; human 01611 [30: E]

A radioimmunoassay for neurotensin in human plasma. Blackburn, A.M., et al.: $J$. Endocrinol., 83, (2) 175 81 (1979) EN human 01612 [30: E]

Epidermal cyclic AMP is not decreased in psoriasis lesions. Adachi, K., et al.: J. Invest. Dermatol., 74, (2) 74 76 (1980) EN 01613 [30: E]

Dead time of scintillation cameras with and without computer. Raikar, U.R., et al.: Int. J. Nucl. Med. Biol., 6, (3) 181 82 (1979) EN 01614 [30: F]

Radiation exposure due to ${ }^{99 m} \mathrm{Tc}$ and ${ }^{131} \mathrm{I}$ manipulated in syringes. Schmidt, W., et al.: Eur. J. Nucl. Med., 4, (5) 389 91 (1979) EN 01615 [30: H]

Nuclear medicine in district general hospitals. Croft, D.: Br. Med. J., 2, (6201) 1336 〜38 (1979) EN 01616 [30: Z]

Sensitometry of films for nuclear medicine. Potter, R., et al.: Eur. J. Nucl. Med., 4, (6) 479 $\sim 82$ (1979) EN 01617 [30: Z] 